\title{
Mathematical modeling of atmospheric fine particle-associated primary organic compound concentrations
}

\author{
Wolfgang F. Rogge, ${ }^{1}$ Lynn M. Hildemann, ${ }^{2}$ Monica A. Mazurek, ${ }^{3}$ and \\ Glen R. Cass \\ Environmental Engineering Science Department and Environmental Quality Laboratory \\ California Institute of Technology, Pasadena \\ Bernd R. T. Simoneit \\ Petroleum and Environmental Geochemistry Group, College of Oceanic and Atmospheric Sciences \\ Oregon State University, Corvallis
}

\begin{abstract}
An atmospheric transport model has been used to explore the relationship between source emissions and ambient air quality for individual particle phase organic compounds present in primary aerosol source emissions. An inventory of fine particulate organic compound emissions was assembled for the Los Angeles area in the year 1982. Sources characterized included noncatalyst- and catalyst-equipped autos, diesel trucks, paved road dust, tire wear, brake lining dust, meat cooking operations, industrial oil-fired boilers, roofing tar pots, natural gas combustion in residential homes, cigarette smoke, fireplaces burning oak and pine wood, and plant leaf abrasion products. These primary fine particle source emissions were supplied to a computer-based model that simulates atmospheric transport, dispersion, and dry deposition based on the time series of hourly wind observations and mixing depths. Monthly average fine particle organic compound concentrations that would prevail if the primary organic aerosol were transported without chemical reaction were computed for more than 100 organic compounds within an $80 \mathrm{~km}$ $\times 80 \mathrm{~km}$ modeling area centered over Los Angeles. The monthly average compound concentrations predicted by the transport model were compared to atmospheric measurements made at monitoring sites within the study area during 1982 . The predicted seasonal variation and absolute values of the concentrations of the more stable compounds are found to be in reasonable agreement with the ambient observations. While model predictions for the higher molecular weight polycyclic aromatic hydrocarbons (PAH) are in agreement with ambient observations, lower molecular weight PAH show much higher predicted than measured atmospheric concentrations in the particle phase, indicating atmospheric decay by chemical reactions or evaporation from the particle phase. The atmospheric concentrations of dicarboxylic acids and aromatic polycarboxylic acids greatly exceed the contributions that are due to direct emissions from primary sources, confirming that these compounds are principally formed by atmospheric chemical reactions.
\end{abstract}

\section{Introduction}

Determination of the partial contributions of the emissions from particular source types to ambient particulate matter concentrations is important both for the design of air pollution control programs in urban areas and for understanding how source effluents become mixed during long range transport over regional and global scales. Methods for assigning aerosol carbon concentrations to their sources are less well developed than for most other air pollution problems. That occurs be-

\footnotetext{
'Now at Department of Civil and Environmental Engineering, Florida International University, University Park, Miami.

${ }^{2}$ Now at Department of Civil Engineering, Stanford University, Stanford, California.

${ }^{3}$ Now at Environmental Chemistry Division, Brookhaven National Laboratory, Upton, New York.

Copyright 1996 by the American Geophysical Union.

Paper number 95JD02050.

0148-0227/96/95JD-02050\$09.00
}

cause so many different source types release carbon particles to the atmosphere and because many of these source effluents appear to be similar in composition if only a total carbon analysis is used to characterize the source emissions and ambient aerosol samples. The problem of source attribution is further complicated by the production in the atmosphere of secondary organic aerosols that result from condensation of the low vapor pressure products of gas phase chemical reactions. The additional possibility that directly emitted particle phase organic compounds may be destroyed by atmospheric chemical reactions also must be considered.

In the present research, unique data sets on the organic chemical composition of both source effluents and atmospheric fine particulate matter have been developed. These data sets provide new opportunities to test our current understanding of the relationships between emissions and air quality for organic aerosols.

First, a comprehensive emission inventory for more than 400 organic compounds that are present in primary organic aerosol 


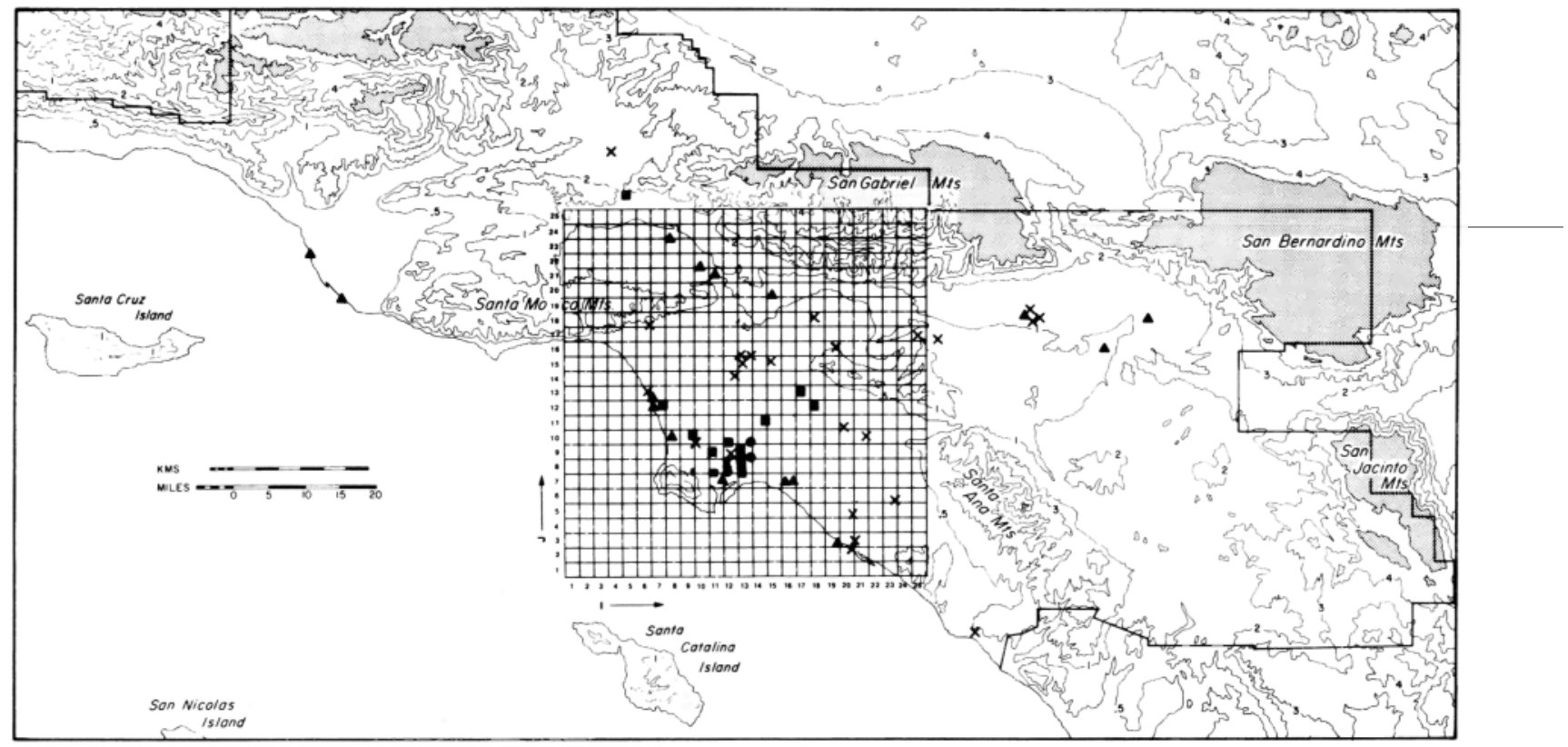

Figure 1. Map of Southern California showing the $80 \mathrm{~km} \times 80 \mathrm{~km}$ gridded modeling region centered over downtown Los Angeles. The lower right corner of the larger area mapped is located in Universal Transverse Mercator (UTM) zone 11 at E $545 \mathrm{~km}$, and $\mathrm{N} 3680 \mathrm{~km}$, and the upper left corner of the larger area mapped is located in UTM zone 11 at E $230 \mathrm{~km}$ and $\mathrm{N} 3840 \mathrm{~km}$.

emissions will be assembled for the $80 \mathrm{~km} \times 80 \mathrm{~km}$ gridded area centered over Los Angeles, California, that is mapped in Figure 1. This emission inventory for single compounds is created by subdividing the inventory for total organic aerosol mass emissions previously reported by Hildemann et al. [1991a]. The combined emissions from the major primary organic aerosol sources acting together first will be compared to measured ambient concentrations of more than 100 particle phase organic compounds. It will be seen that there is an obvious and close correspondence between these two data sets for the case of the least chemically reactive compounds studied.

Next, the emission inventory data will be matched to an existing mathematical model for atmospheric transport and dilution. The time series of the concentrations of single organic compounds and major compound classes found in the particle phase that would be expected in the absence of any further atmospheric chemical reactions will be computed in the Los Angeles area for each month of the year 1982. Comparisons will be drawn between the predicted source contributions to ambient organic aerosol compound concentrations versus the concentrations measured at west Los Angeles, downtown Los Angeles, and Pasadena by Rogge et al. [1993a]. Evidence for the production of secondary organic aerosols and for the degradation of primary organic species by volatilization and/or chemical reaction will be sought through examination of the source and ambient data sets.

\section{Model Description}

Atmospheric pollutant transport through the Los Angeles basin is driven by differential solar heating of the land and sea, leading to a daily cyclic land and sea breeze. During morning and early evening hours the winds are often stagnant with no prevailing direction over short observation times of 1 hour or less. From midday until late afternoon the wind typically blows from the ocean toward the land. At night, slow drainage winds proceed from the land toward the sea. In addition to the daily land-sea wind reversal, there is a strong diurnal variation in the height of the base of the atmospheric temperature inversion over the Los Angeles basin. In the early morning, with the onset of solar heating of the land, the inversion base rises progressively until the afternoon. In the evening, cooling by reradiation from the ground or continued subsidence causes the inversion base to descend again.

An air quality model that predicts long-term average nonreactive pollutant concentrations for the unsteady meteorological conditions just described was originally developed by Cass [1977, 1981] and later modified by Gray [1986] to predict elemental and total organic fine particulate carbon concentrations in the greater Los Angeles area atmosphere. Because of the unsteady flow field that is typically encountered in the Los Angeles area, a Lagrangian particle-in-cell modeling technique was chosen that simulates advection, dispersion, and deposition of pollutants in response to the hourly time sequence of the measured winds and the daily fluctuating height of the temperature inversion aloft. The transport predictions of that model subsequently have been verified against ambient measurements of black elemental carbon particles [Gray, 1986], chromatographable organic compound mass concentrations [Hildemann et al., 1993], and carbon isotope concentrations [Hildemann et al., 1994a].

Because the model used here has been described in detail and tested thoroughly on several previous occasions [Cass, 1977, 1981; Gray, 1986; Hildemann et al., 1993, 1994a], only a brief description of its principles of operation will be given here. Hypothetical mass points marked with the mass emission rate of particulate organic compounds are released successively at short time intervals from each source type separately at the effective stack height of the source of interest. The $80 \mathrm{~km}$ 
$\times 80 \mathrm{~km}$ area centered over Los Angeles shown in Figure 1 is subdivided into 625 computational cells of size $3.2 \mathrm{~km} \times 3.2$ $\mathrm{km}$ each, and each source is located within its appropriate grid cell. Depending on the effective stack height (actual stack height $h$ plus plume rise $\Delta h$ ), the source emissions can be injected either below or above the base of the atmospheric temperature inversion. Fluid parcels that are either above or below the inversion base can be exchanged, depending on the ascent or descent of the base of the temperature inversion with time. For fine particulate source emissions inserted below the inversion base, three vertical transport regimes are considered: (1) when the inversion base height is substantially higher than the effective stack height of the pollutant source, the inversion base has no effect on the initial vertical dispersion of the plume, and the pollutant concentration assumes a Gaussian distribution in the vertical domain; (2) as the air parcel moves away from its source, the vertical dispersion increases until the inversion layer begins to trap the air parcel below; and (3) far from the source, the plume becomes completely mixed between the ground and the inversion base.

Trajectories of single fluid parcels starting from each source form streaklines that are computed from the hourly time series of ground level wind speed and direction. Horizontal diffusion is then simulated by adding small displacements to each air parcel location at each hour, which are drawn from a Gaussian distribution that expands with downwind travel time in accordance with the experimental observations on atmospheric dispersion rates over the metropolitan Los Angeles area measured by Drivas and Shair [1975] and F. H. Shair (personal communication, 1977), as organized by Cass [1981].

The ambient pollutant concentration within the ground level layer of each computational cell is obtained by integrating over the magnitude and location of all pollutant parcels that fall within the ground level layer of that cell. Computationally, the monthly average pollutant concentration increments $\overline{(c(\mathbf{x} ; T}$, $\overline{\left.\left.t_{s}\right)\right\rangle}$ at each receptor site are obtained by evaluating the Lagrangian formulation of the atmospheric dispersion equation, as follows:

$$
\begin{aligned}
& \overline{\left\langle c\left(\mathbf{x} ; T, t_{s}\right)\right\rangle}=\int_{-\infty}^{+\infty} \int_{-\infty}^{+\infty} \int_{-\infty}^{+\infty} \\
& \cdot\left[\frac{1}{T} \int_{t_{s}}^{t_{s}+T} \int_{0}^{+\infty} Q\left(\mathbf{x}, t \mid \mathbf{x}^{\prime}, t-\tau\right) \omega(t-\tau) d \tau d t\right] \bar{S}\left(\mathbf{x}^{\prime}\right) d \mathbf{x}^{\prime}
\end{aligned}
$$

where $Q\left(x, t \mid \mathbf{x}^{\prime}, t-\tau\right)$ is the transition probability density function that describes the probability that a fluid particle will be found at location $\mathbf{x}$ at present time $t$ given that it was located previously at $\mathbf{x}^{\prime}$ at time $t-\tau$ (these probabilities are computed by tracking the fluid particles through the simulation of horizontal and vertical transport described earlier); $\omega(t-\tau)$ is the normalized diurnal variation in the emission rate for the source type of interest; $\bar{S}\left(\mathbf{x}^{\prime}\right)$ is the time-averaged source strength at location $\mathrm{x}^{\prime}$ of the source class of interest; $T$ is the length of the averaging time (in our case $T$ equals 1 month); and $t_{s}$ is the starting time. Finally, by adding all incremental concentration contributions from all source classes and by superimposing these monthly average concentrations onto an estimate of organic aerosol' kground air quality, estimates of the ambient organic ae a concentrations due to primary emissions of particulate matter from all sources acting together are obtained.

\section{Prior Model Application}

The air quality model discussed above has been applied by Gray [1986] to predict monthly average concentration levels for fine particulate elemental carbon (EC) and total carbon (TC) at seven urban monitoring sites within the Los Angeles study area for the year 1982. As part of the input data prepared for that model simulation, an inventory of fine carbon particle emissions was compiled for mobile, as well as stationary, sources that are located within the modeling domain. The spatial and temporal distribution of emissions was estimated for over 70 different source types. Emissions from point sources were assigned to the actual locations of those sources. These point sources include all major sources emitting over 25 tons of particulate matter per year, such as large power plants and petroleum refineries, and also thousands of smaller permitted facilities (falling into 178 categories) that are carried as separate entries within the emissions database maintained by the California Air Resources Board. Residential source emissions were distributed throughout the grid system in proportion to population density. Vehicular exhaust emissions were allocated to the grid system in proportion to traffic densities observed on surface streets and freeways. For all other source classes the source locations and emissions strengths were extracted from a spatially distributed emission inventory forecast provided by the California Air Resources Board [see Gray, 1986]. Seasonal changes in fuel consumption, for example, fireplace combustion of wood, were surveyed for fuel combustion sources. Other source classes were assumed to operate without any seasonal trend. Emissions from sources that have a pronounced diurnal operation pattern were represented in the model through estimation of the function $\omega(t-\tau)$ that appears in (1) for each source type.

Paved road surfaces act as a repository for dirt and dust that has settled out of the atmosphere. Under suitable conditions these road dust deposits are reentrained into the atmosphere as a function of traffic density, wind speed, and other meteorological conditions. It is difficult to assess the daily emission rate of fine particulate road dust. Therefore Gray [1986] specified a receptor modeling approach in which $\mathrm{Al}$ and $\mathrm{Si}$ tracer concentrations in airborne fine particulate matter and in fine paved road dust are used to derive from actual ambient measurements an upper limit on the road dust contributions to the ambient aerosol complex. That approach will be used to model road dust contributions to ambient air quality in the present study as well. For a more detailed discussion, see Gray [1986]. In addition to source emission data, other model input data include hourly wind fields that were computed from observed data over central Los Angeles and paired with hourly mixing depth data that were obtained by impressing a diurnal pattern onto the morning and afternoon mixing depth measurements reported daily by the South Coast Air Quality Management District.

To evaluate the performance of the model, ambient fine particulate matter samples were collected at $\mathbf{1 0}$ urban sampling sites and one remote offshore sampling site at 6-day intervals throughout the entire year 1982 [Gray et al., 1986]. The duration of each sampling period was 24 hours. Typically, good agreement was found between modeled and measured ambient EC and TC concentrations [see Gray, 1986]. 
Table 1. Fine Aerosol Organic Carbon (OC) Emissions within the $80 \mathrm{~km} \times 80 \mathrm{~km}$ Study Area Centered Over Los Angeles for 1982

\begin{tabular}{|c|c|c|c|}
\hline Source Categories & $\begin{array}{c}\text { OC Emitted, } \\
\text { kg/day }\end{array}$ & $\begin{array}{l}\text { Profile No. of Source } \\
\text { Tested in This Study }\end{array}$ & $\begin{array}{l}\text { Source Profile Used } \\
\text { for Modeling }\end{array}$ \\
\hline \multicolumn{4}{|l|}{ Catalyst-equipped gasoline vehicles } \\
\hline Catalyst-equipped autos & 780 & 1 & 1 \\
\hline Other catalyst-equipped vehicles ${ }^{b}$ & 79 & & 1 \\
\hline \multicolumn{4}{|l|}{ Noncatalyst gasoline vehicles } \\
\hline Noncatalyst autos & 2088 & 2 & 2 \\
\hline Other noncatalyst vehicles ${ }^{c}$ & 1372 & & 2 \\
\hline \multicolumn{4}{|l|}{ Diesel vehicles } \\
\hline Diesel heavy-duty trucks & 1242 & 3 & 3 \\
\hline Railroad diesel locomotives & 211 & & 3 \\
\hline Diesel ships & 42 & & 3 \\
\hline Other diesel vehicles $^{d}$ & 617 & & 3 \\
\hline \multicolumn{4}{|l|}{ Brake and tire dust } \\
\hline Tire dust & 414 & 4 & 4 \\
\hline Brake lining attrition & 690 & 5 & 5 \\
\hline \multicolumn{4}{|l|}{ Paved road dust } \\
\hline Paved road dust & 4728 & 6 & 6 \\
\hline \multicolumn{4}{|l|}{ Natural gas combustion } \\
\hline Natural gas, residential/commercial & 30 & 7 & 7 \\
\hline Natural gas, other sources ${ }^{e}$ & 262 & & 7 \\
\hline Refinery gas & 195 & & 7 \\
\hline LPG combustion & 10 & & 7 \\
\hline \multicolumn{4}{|l|}{ Stationary source fuel oil combustion } \\
\hline Residual oil, stationary sources $f$ & 206 & & 8 \\
\hline Distillate oil, industrial boilers ${ }^{g}$ & 13 & 8 & 8 \\
\hline Other distillate oil combustion ${ }^{h}$ & 23 & & 8 \\
\hline Industrial internal combustion gasoline engines & 19 & & 2 \\
\hline \multicolumn{4}{|l|}{ Wood combustion } \\
\hline Pine wood burned in fireplaces & 3332 & 9 & 9 \\
\hline Oak wood burned in fireplaces & 840 & 10 & 10 \\
\hline Structural fires ${ }^{\ell}$ & 63 & & 9 \\
\hline \multicolumn{4}{|l|}{ Meat cooking } \\
\hline Charbroiling meat & 4938 & 11,12 & 11 \\
\hline Frying meat & 1393 & 13 & 13 \\
\hline \multicolumn{4}{|l|}{ Cigarette smoke } \\
\hline Cigarettes & 802 & 14 & 14 \\
\hline \multicolumn{4}{|l|}{ Roofing } \\
\hline Roofing tar pots & 556 & 15 & 15 \\
\hline Asphalt roofing manufacturing & 81 & & 15 \\
\hline \multicolumn{4}{|l|}{ Vegetation } \\
\hline Green leaf abrasion products ${ }^{k}$ & $\mathbf{N K}^{l}$ & 16 & 16 \\
\hline \multirow{2}{*}{\multicolumn{4}{|c|}{ Other sources not modeled }} \\
\hline & & & \\
\hline Surface coating & 1433 & & \\
\hline Forest fires & 877 & & \\
\hline Organic chemical processes & 692 & & \\
\hline Miscellaneous industrial point sources & 393 & & \\
\hline Miscellaneous petroleum industry processes & 278 & & \\
\hline Primary metallurgical processes & 228 & & \\
\hline Secondary metallurgical processes & 167 & & \\
\hline Mineral industrial processes & 158 & & \\
\hline Other organic solvent use & 106 & & \\
\hline Jet aircraft & 92 & & \\
\hline Coal burning & 76 & & \\
\hline Wood processing & 74 & & \\
\hline Residual oil, fired ships & 66 & & \\
\hline Other sources & 156 & & \\
\hline Total & 29822 & & \\
\hline
\end{tabular}

LPG, liquified petroleum gas.

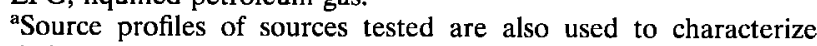
emissions from similar source types.

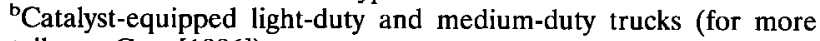
detail, see Gray [1986]).

'Noncatalyst light-duty trucks, medium-duty trucks, heavy-duty trucks, off-road gasoline vehicles, and motorcycles (for more detail, see Gray [1986]).

${ }^{d}$ Diesel autos, diesel light-duty trucks, off-road diesel vehicles (for more detail, see Gray [1986]).

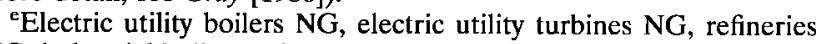
NG, industrial boilers NG; NG, natural gas used (for more detail, see Gray [1986]).

'Electric utility boilers burning residual oil, refineries burning residual oil, industrial boilers burning residual oil, residential/commercial combustion of residual oil (for more detail, see Gray [1986]).

${ }^{g}$ Average compound emission rates from two single source tests are used [see Rogge et al., 1994c].

${ }^{h}$ Residential/commercial distillate oil combustion, electric utilities burning distillate oil (for more detail, see Gray [1986]).

'Structural fires are assumed to show a similar organic compound profile as found for pine wood combustion in residential fireplaces.

${ }^{\prime}$ Profile number 11: charbroiling regular hamburger meat with a fat content of $21 \%$; profile number 12 : charbroiling extralean meat with a fat content of $10 \%$.

${ }^{k}$ For model calculations, only the source profile derived from green leaf abrasion products is used [see, Rogge et al., 1993d].

${ }^{\prime} \mathrm{NK}$, emission rate not known. Modeled concentrations based in fitting to high molecular weight $n$-alkanes. 
Recently, the same model and meteorological data were used to predict primary organic aerosol characteristics and carbon isotope concentrations from measured source emissions [Hildemann et al., 1993, 1994a]. To complement the ambient sampling program conducted by Gray et al. [1986] in 1982 , the major urban source types were tested that together represent close to $80 \%$ of the primary organic carbon emissions to the Los Angeles atmosphere [Hildemann et al., 1991a]. These source test results were used to modify the primary aerosol organic carbon (OC) emission inventory originally compiled by Gray [1986]. That revised emission inventory is shown in Table 1. The organic aerosol characteristics of both source samples and ambient samples were defined through measurements of elutable organic matter as detected by a high-resolution gas chromatograph (GC) equipped with a flame ionization detector system [Hildemann et al., 1991b, 1994b]. A 52-parameter "fingerprint" was constructed to characterize the emissions from each source type by measuring the quantity of the organic compounds eluting from the GC column in both the nonpolar and polar fractions of each source sample between the successive elution points of the $C_{12}$ to $C_{36}$ $n$-alkanes. The data on the mass emissions from each source type within each GC elution zone defined above were entered into the air quality model. The model was then used to predict the characteristic distribution of organic aerosol mass as a function of polarity and elution time that would be found in ambient air if these source effluents were transported without chemical reaction. Model results were compared against high resolution GC measurements of ambient samples taken at west Los Angeles, downtown Los Angeles, and Pasadena [Hildemann et al., 1993]. Model results for the nonpolar fraction of the atmospheric organic aerosol that is characteristic of primary carbon particle sources were reliably found to be within the error bounds on the atmospheric samples to which the model was compared.

\section{Present Model Application}

In the present study, ambient concentrations of individual organic compounds that are associated with the fine particulate source emissions are predicted. The OC emission inventory originally compiled by Gray [1986] and updated by Hildemann et al. [1991a] is combined with the chemical characterization of the single organic compound emissions found in the particle phase from each source that has been presented by Rogge et al. [1991, 1993b, c, d, e, 1994; W. F. Rogge, L. M. Hildemann, M. A. Mazurek, G. R. Cass, and B. R. T. Simoneit, Sources of fine organic aerosol, 7, Hot asphalt roofing tar pot fumes; 8, Boilers burning No. 2 distillate fuel oil; 9, Fireplace combustion of wood, submitted to Environmental Science and Technology, 1995, hereinafter referred to as Rogge et al., submitted manuscript, 1995a, b, and c, respectively]. These emissions data are supplied to the air quality model along with the meteorological data set developed by Gray [1986] and are used to predict monthly average organic compound concentrations over the year 1982. Predicted ambient concentrations are compared to the measured ambient organic compound concentrations reported by Rogge et al. [1993a].

\section{Organic Compound Aerosol Source Profiles}

The fine particle samples collected during the previous source testing campaign [Hildemann et al., 1991a] were ana- lyzed using gas chromatography-mass spectrometry (GCMS) techniques [Rogge et al., 1991, 1993b, c, d, e, 1994; submitted manuscripts, 1995a, b, c]. Organic chemical composition profiles for 18 source types were generated that together include roughly 400 different organic compounds.

Ambient samples used in this study included particulate matter collected at west Los Angeles, downtown Los Angeles, Pasadena, and Rubidoux (outside the modeling region to the east) during the year 1982 [Gray, 1986]. The filter samples were composited month-by-month prior to analysis. All fine particle samples, including the source and ambient samples, were collected using comparable equipment and materials and were processed by the same analytical extraction technique [ $\mathrm{Ma}$ zurek et al., 1987, 1989]. All source and ambient samples were characterized and quantified by the same GCMS techniques as described in full detail by Rogge et al. [1991, 1993b, c, d, e, 1994; submitted manuscripts, 1995a, b, c].

\section{Individual Emission Sources Considered}

A multitude of different urban sources contribute fine particulate matter to the urban atmosphere. Of the more than 70 source types included in the inventory compiled by Gray [1986], sources were chosen that are either directly represented by the authentic source profiles available [Rogge et al., 1991, 1993b, c, d, e, 1994; submitted manuscripts, 1995a, b, c] or that are closely related to the sources tested. Sources for which detailed organic chemical composition data are available from source tests conducted during the present program are identified by a source profile number entered in the second numerical column of Table 1 . Sources used within the model include both those that were tested directly and those whose composition can be represented closely by a source that was tested, as indicated in the far right column of Table 1. For example, source profile number 2 obtained for the noncatalyst gasoline-powered vehicles tested is also applied to noncatalyst light-duty trucks, medium-duty gasoline-powered trucks, heavy-duty gasoline-powered trucks, off-road gasolinepowered vehicles, and motorcycles. Those minor sources listed in Table 1 for which no close match can be made to a source composition profile, and therefore lack an entry in the far right column of Table 1, are excluded from the model. Sources that are included in the model account for $83.4 \%$ of the primary OC emissions within the Los Angeles area. In order to organize the discussion of the modeling results, the sources included within the model are further grouped into 12 source categories that form the first 12 major subdivisions in Table 1.

Before using the organic compound source data sets to model respective ambient concentrations the overall daily emission rates of organic compound mass based on the $\mathrm{OC}$ emission inventory will be discussed. Next, the total daily single compound emission rates (kilograms per day) summed over all source categories will be compared to the measured monthly ambient organic compound concentrations, determined as the mean of the monthly concentrations measured at west Los Angeles, downtown Los Angeles, and Pasadena. Finally, ambient organic compound concentrations will be estimated from the emissions data using the air quality model. 
(a)
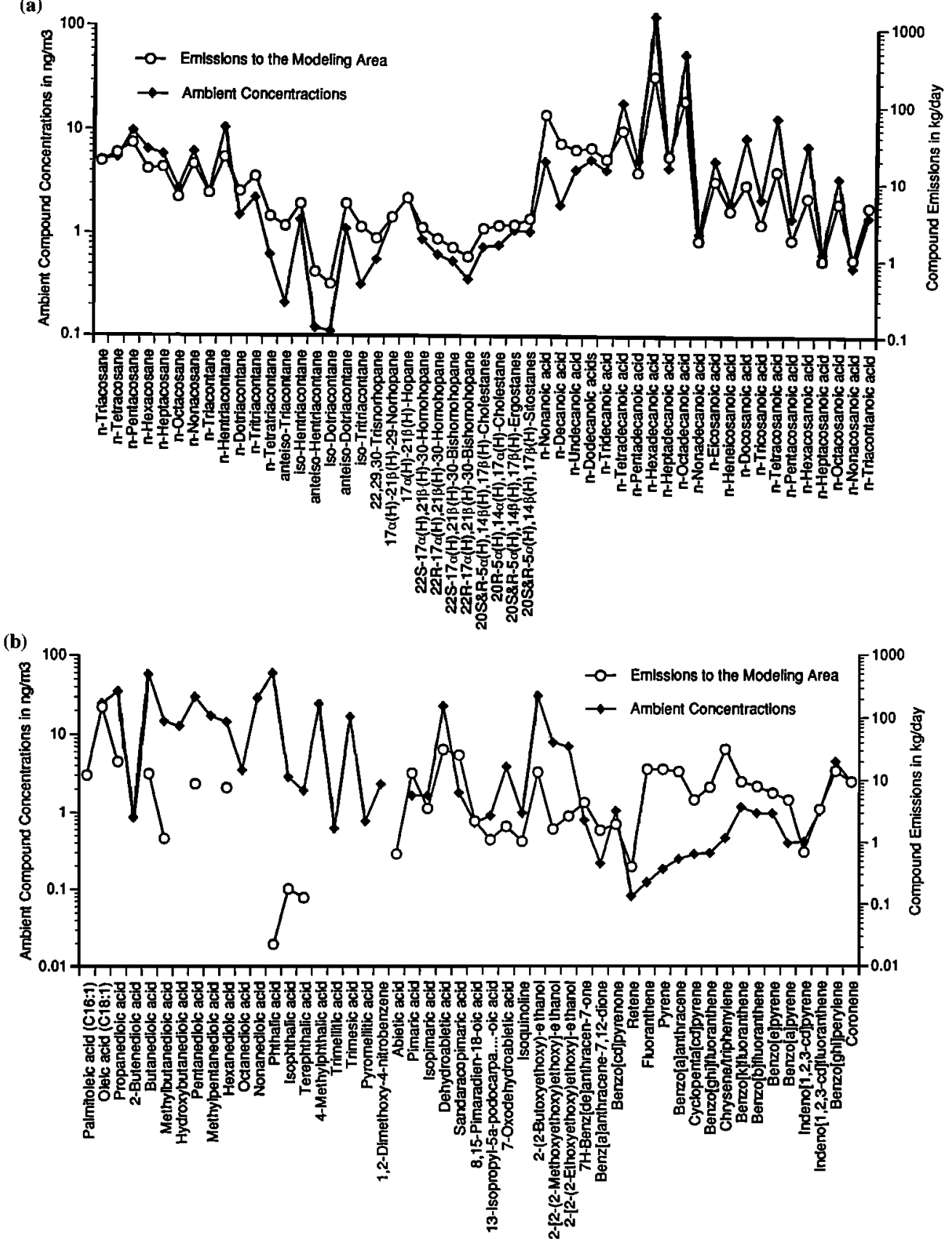

Figure 2. Comparison between compound emission rates and ambient concentrations.

\section{Ambient Concentrations Versus Daily Emission Rates for Single Organic Compounds Found in the Particle Phase}

In the study by Gray [1986] a known stable tracer EC was used to confirm transport calculations. In the current study, single organic compounds are tracked that may be partitioned between the gas phase and the particle phase and whose chemical stability in the urban atmosphere is often unknown. Therefore it is useful at the outset of the present work to examine the source and ambient data sets for evidence that the two data sets are or are not clearly related to one another.

One possible method to deduce qualitative information regarding single organic compound stability is to graphically compare the daily organic compound emission rates with am- bient concentration data on a compound-by-compound basis. Discrepancies between these two data sets can occur as a result of the following reasons: (1) some emissions sources might remain unidentified; (2) the most volatile particle-associated compounds might partition to the gas phase following their emission to the atmosphere in the presence of diurnal temperature variations; (3) semivolatile compounds might react preferentially in the gas phase causing a net flux from the particle phase to the gas phase as concentrations reequilibrate; and (4) heterogeneous chemical reactions might occur on the particle surface itself, causing a loss of certain reactive compounds. Very limited knowledge presently exists concerning the atmospheric stability of semivolatile and reactive nonvolatile or ganic compounds. The current study will provide at least a 
qualitative examination of the likely stability of such compounds.

Figures $2 a$ and $2 b$ show the primary emissions of single organic compounds in kilograms per day released to the atmosphere of the Los Angeles study area for 101 organic compounds that are present in both the source and ambient data sets. The annual mean ambient compound concentrations averaged over all measurements made at west Los Angeles, downtown Los Angeles, and Pasadena throughout the entire year 1982 are shown on the same graph. The alignment of the emissions and ambient concentration axes is arbitrary; no air quality modeling calculations are involved here.

Figure 2a shows that organic compounds such as the $n$ alkanes, isoalkanes and anteisoalkanes, higher molecular weight $n$-alkanoic acids, and fossil petroleum compounds, including hopanes and steranes, display changes in relative emission rates between compounds that are quite similar to the measured relative abundance of such compounds in ambient air. This indicates that such particle-bound compounds are relatively stable chemically, at least for the time that it takes for the transport from the sources to the ambient monitoring sites. For lower molecular weight $n$-alkanoic acids $\left(C_{9}-C_{14}\right)$ the emission profile is somewhat elevated compared to the ambient concentration profile. Possibly, such low molecular weight $n$-alkanoic acids are lost from the fine aerosol phase via volatilization or chemical reaction.

Palmitoleic acid $\left(C_{161}\right)$ and oleic acid $\left(C_{181}\right)$ are two unsaturated fatty acids that are mainly released from meat-cooking operations within the current emission inventory. While oleic acid was identified in the atmospheric aerosol samples, palmitoleic acid was not found (see Figure $2 b$ ). This difficulty in measuring palmitoleic acid in the atmosphere could be due to its low emission rate compared to oleic acid, to its higher volatility and possible degradation in the gas phase, or to heterogeneous attack on the double bond by ozone or other radicals yielding, in part, aliphatic dicarboxylic acids, as suggested by several researchers [e.g., Kawamura and Kaplan, 1987; Killops, 1986].

Aliphatic dicarboxylic acids and aromatic polycarboxylic acids have been quantified in the ambient aerosol characterization study conducted by Rogge et al. [1993a]. Both compound classes are important because of their possible formation by chemical reactions in the atmosphere [Grosjean, 1977; Grosjean and Friedlander, 1980; Grosjean and Seinfeld, 1989; Hatakeyama et al., 1985, 1987; Rogge et al., 1993a; Tao and McMurry, 1989]. During the source emission characterization campaign, aliphatic dicarboxylic and aromatic polycarboxylic acids have been found only in trace amounts in the emissions of some of the sources tested. Accordingly, the ambient compound concentration profile is not matched at all by the source emission profile for these compounds, as indicated in Figure $2 \mathrm{~b}$. This in turn suggests that such aliphatic and aromatic polycarboxylic acids are indeed of secondary origin, formed by atmospheric chemical processes.

Moving to the right in Figure 2b, the next group of compounds, resin acids, are mainly released during the combustion of pine wood in fireplaces in Southern California. Abietic acid is released only in small amounts and therefore is below detection limits in the ambient samples. Polyalkylene glycol ethers (e.g., 2-(2-butoxyethoxy)-ethanol) that are typically used as hydraulic fluids (e.g., in vehicle braking systems [Rogge et al., 1993c]) show a pattern of relative concentrations that is similar between the sources and ambient data; however, the absolute magnitude of the ambient concentrations seems to exceed the known emission rates. This suggests that there are sources of these compounds other than brake dust.

While higher molecular weight $\mathrm{PAH}$, such as indeno[1,2,3cd]pyrene, indeno[1,2,3-cd]fluoranthene, benzo[ghi]perylene, and coronene, show close agreement between ambient concentration and emission rate data, lower molecular weight $\mathrm{PAH}$ (e.g., fluoranthene, pyrene, and others) show concentrations significantly lower than emission data would suggest. This suggests that such low molecular weight PAH may preferably degrade in the gas phase by photochemical processes and radical attack [Kamens et al., 1990; Pitts et al., 1969, 1978, 1980, 1985; Lane and Katz, 1977; Van Cauwenberghe, 1983], which leads in turn to further volatilization of such particle phase associated PAH in an attempt to restore the gas-particle phase equilibrium. Alternatively, the low molecular weight PAH may be degraded by heterogeneous chemical reactions between gas phase oxidants and particle phase $\mathrm{PAH}$.

\section{Observed Versus Predicted Organic Compound Concentrations}

Ambient concentrations of fine particle-associated organic compounds that are emitted from the urban sources listed in Table 1 are predicted using a mathematical model that simulates release to and transport in the urban atmosphere. Fine particulate road dust contributions are estimated separately using a source-receptor modeling approach based on $\mathrm{Al}$ and $\mathrm{Si}$ as tracers for the soil content of road dust, as outlined earlier. The ambient fine organic aerosol source contributions from each of these urban sources are superimposed onto background organic aerosol concentrations measured upwind of Los Angeles at San Nicolas Island [Rogge et al., 1993a]. Model predictions for west Los Angeles, downtown Los Angeles, and Pasadena are compared against actual measured data. To simplify the visual presentation of these results in the figures that follow, the large number of source types modeled have been collected into 12 groups of similar sources that form the first 12 major subdivisions in Table 1.

The air quality model treats all organic compound emissions as if they were chemically stable in the atmosphere. Hence (1) the "perfect model" would predict ambient concentration levels of "stable" organic compounds that match perfectly the measured ambient concentrations. In contrast, (2) if chemically reactive organic compounds are emitted that degrade rapidly in the atmosphere, then the present model which tracks dispersion alone will produce higher predicted ambient concentrations than are actually observed. Furthermore, (3) organic compounds that are found in only trace amounts in primary source emissions, but that are measured in substantial quantities in the urban atmosphere, must be the result of atmospheric chemical formation from gas phase precursor compounds (secondary aerosol).

In the discussion that follows, model performance will be judged by comparison of predicted to observed concentrations of the most stable organic compounds considered. Compounds that decay by reaction in the atmosphere and compounds that are formed from gas phase precursors will be discussed as two separate categories, where the degree of atmospheric transformation can be judged by comparison to the model result that would have been obtained in the absence of any atmospheric chemical reactions. 


\section{Including Vegetative Detritus as an Additional Source}

Leaves of plants and trees show a waxy surface layer that when magnified consists of waxy protrusions of micron and submicron dimensions [e.g., Simoneit, 1977, 1979]. When entrained into the atmosphere as a result of the action of wind and weather, such fine particulate leaf surface abrasion products show a characteristic predominance of odd over even carbon numbered $n$-alkanes, typically with highest concentrations for the $\mathrm{C}_{29}, \mathrm{C}_{31}$, and $\mathrm{C}_{33}$ n-alkanes [Kolattukudy, 1970; Mazurek and Simoneit, 1984; Mazurek et al., 1991; Simoneit et $a l ., 1988,1991]$. This concentration pattern is more or less preserved in ambient total and fine particulate matter. Similarly, such leaf abrasion products reveal a characteristic predominance of even over odd carbon numbered $n$-alkanoic acids [Simoneit and Mazurek, 1982; Rogge et al., 1993d].

While the emission rate of vegetative detritus to the atmosphere is not yet known, an upper limit to the magnitude of the concentration increment present because of this source has been estimated for Los Angeles by Hildemann et al. [this issue] on the basis of the presence in the atmosphere of high molecular weight $n$-alkanes that show the odd carbon number predominance characteristic of plant waxes. In that study, model predictions for $n$-alkanes were first calculated by including within the transport model all sources except vegetative detritus emissions. The measured concentrations of the $C_{29}$ and $C_{31}$ $n$-alkanes are appreciably higher than those predicted by the model, indicating, as expected, that an important contribution from vegetative detritus is missing. To derive an upper bound estimate of the fine particulate leaf surface abrasion products contributions to the ambient aerosol complex, the following approach has been chosen: the distribution of $\mathrm{C}_{28}$ to $\mathrm{C}_{34} n$ alkanes present in the emissions of green leaf abrasion products is matched against the difference between measured minus predicted ambient $n$-alkane concentrations. The fitting process was conducted by least squares regression analysis for each month at each site. The ambient concentrations of all other organic compounds that are emitted as part of the leaf abrasion products are determined in proportion to the $\mathrm{C}_{28}-\mathrm{C}_{34}$ $n$-alkane content attributed to leaf abrasion products, and these concentration increments are then added to the respective predicted ambient compound concentrations.

\footnotetext{
Alkanes

Figures $3 a$ and $3 b$ show air quality model predictions of the annual mean source contributions to $n$-alkane concentrations, including the estimated contributions from vegetative detritus (12 source categories). The $n$-alkanes considered here fall into two groups according to their origin. The $n$-alkanes $<\mathrm{C}_{27}$ mainly originate from sources burning fossil fuels, while $n$ alkanes $>C_{27}$ come to an appreciable extent from cigarette smoke and leaf surface abrasion products. While the $\mathrm{C}_{29}$ and $\mathrm{C}_{31} n$-alkane concentration predictions fit well with the respective measured ambient concentrations, the concentration of the $\mathrm{C}_{33} n$-alkane is overpredicted by roughly a factor of 2 . This discrepancy results from the fact that the leaf composites from which the vegetative detritus source sample was generated (made up of 62 plant species typically found in the Los Angeles area [Hildemann et al., 1991a; Rogge et al., 1993d]) show a relatively higher $\mathrm{C}_{33} n$-alkane concentration than is observed in the Los Angeles urban atmosphere (for further discussion, see Hildemann et al. [this issue]).
}
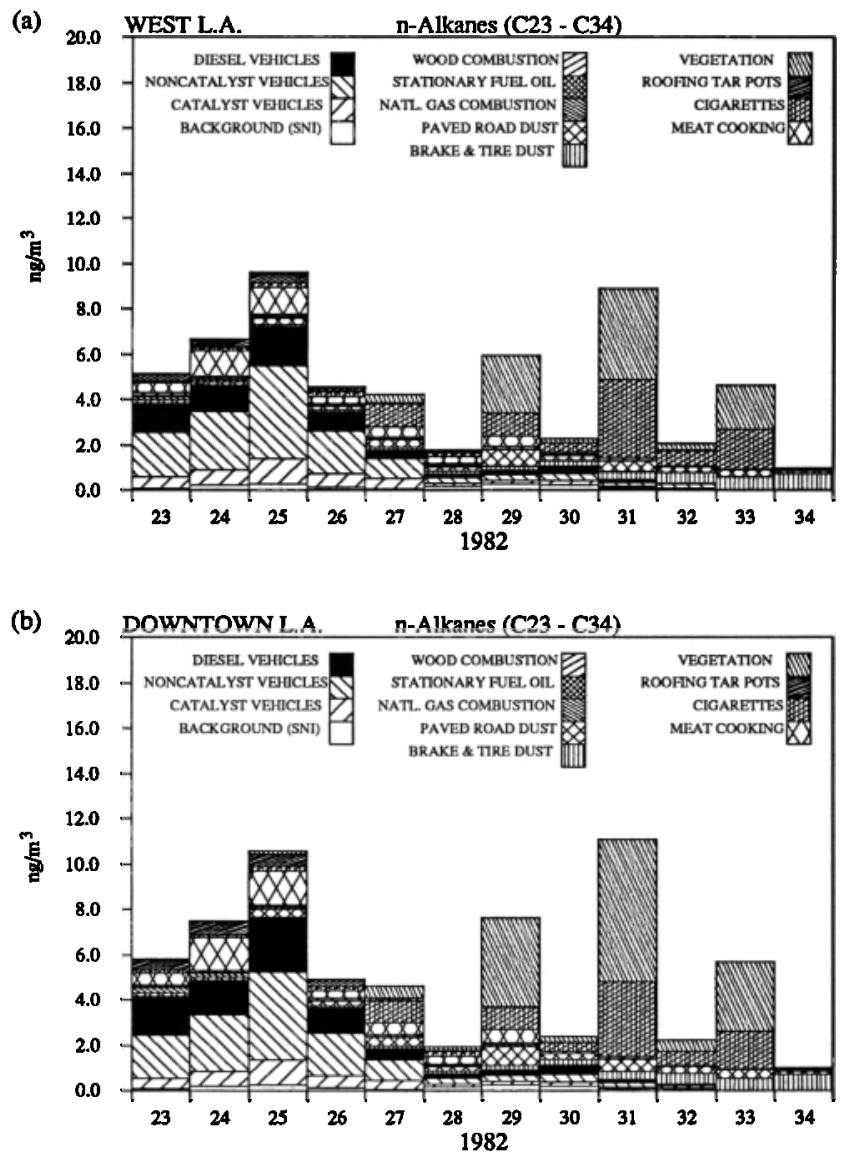

Figure 3. Annual mean $n$-alkane concentration predictions, including contributions from vegetative detritus (1982): (a) west Los Angeles and (b) downtown Los Angeles.

The time series of predicted monthly averaged total $n$ alkane $\left(\mathrm{C}_{23}-\mathrm{C}_{34}\right)$ concentration predictions are compared to the measured concentrations for the entire year 1982 at west Los Angeles in Figures $4 \mathrm{a}$ and $4 \mathrm{~b}$. The predicted total $n$-alkane concentrations agree very well with the observations, with a little overprediction in late summer and a small underprediction in November and December. The major source categories contributing include all three vehicle types tested, cigarette smoke, and leaf abrasion products from urban vegetation. At downtown Los Angeles the measured total $n$-alkane concentrations are very close to the model predictions from February through October, but during January, November, and December, the observed values are higher than predicted. At Pasadena both predicted and measured total $n$-alkane concentration profiles show, except during January, an ambient concentration pattern that has little seasonal variation. Most of the anthropogenic sources, such as motor vehicles, emit particulate matter at a nearly constant rate throughout the year. The decline in concentrations in the spring and summer months is due to increased dilution by meteorological conditions such as higher wind speeds and greater mixing depths at that time of year rather than to a decline in emission rates. Wood smoke emissions are an exception to this rule; wood smoke emissions fall nearly to zero during the warmer months.

Figures $5 \mathrm{a}$ and $5 \mathrm{~b}$ show the observed and predicted concentrations of $n$-pentacosane $\left(\mathrm{C}_{25}\right)$, the major fossil fuel combustion-derived $n$-alkane. The ambient concentrations are seen to 
be dominated by motor vehicle exhaust. Comparing the observed with predicted $n$-pentacosane concentrations at each of the sites, typically reasonably good agreement exists, except during January, November, and December, at downtown Los Angeles and Pasadena, where the nominal measured concentrations are higher than predicted.

The compound $n$-hentriacontane, the most prominent member of the leaf wax group of high molecular weight $n$-alkanes (cigarette smoke and release of leaf surface abrasion products), shows a seasonal concentration pattern with less pronounced summer-winter differences than was observed for $n$ pentacosane (compare Figures 5a and 6a). Surprisingly, cigarette smoke adds amounts of higher molecular weight $n$ alkanes to the urban atmosphere that are comparable to the contributions from vegetative detritus, as shown in Figure 6b. Despite different release mechanisms, these compounds originate from the plant waxes in both cases.

Recently, Rogge et al. [1994] isolated higher molecular weight branched alkanes in cigarette smoke that reveal a unique concentration pattern not matched by any other known sources in Los Angeles. Hence these higher molecular weight branched alkanes with isohentriacontane and anteisodotriacontane as the most prominent members were proposed as possible markers that can be used to trace cigarette smoke in the urban atmosphere. The model predictions shown in Figure 7 reveal good agreement between observed and predicted isohentriacontane and anteisodotriacontane concentrations, sup-

(a)
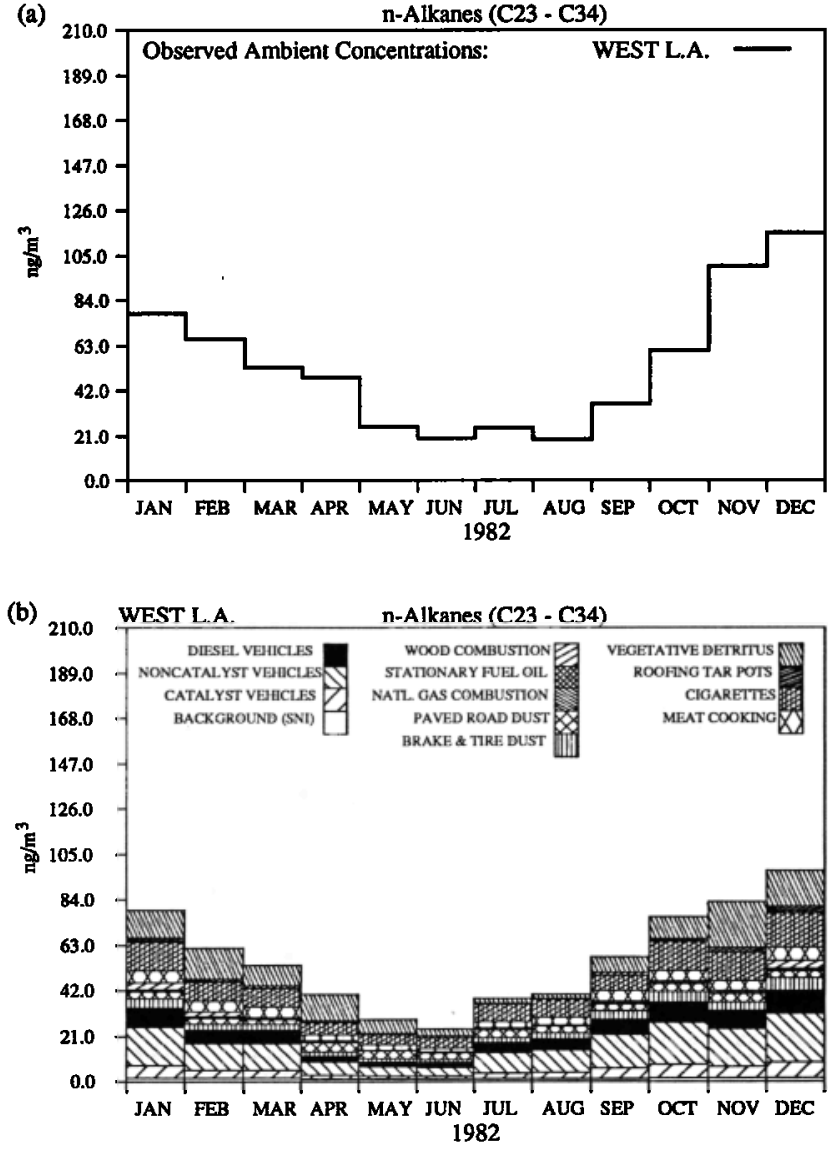

Figure 4. Monthly mean $n$-alkane concentrations at west Los Angeles (1982): (a) observed and (b) predicted source contributions.
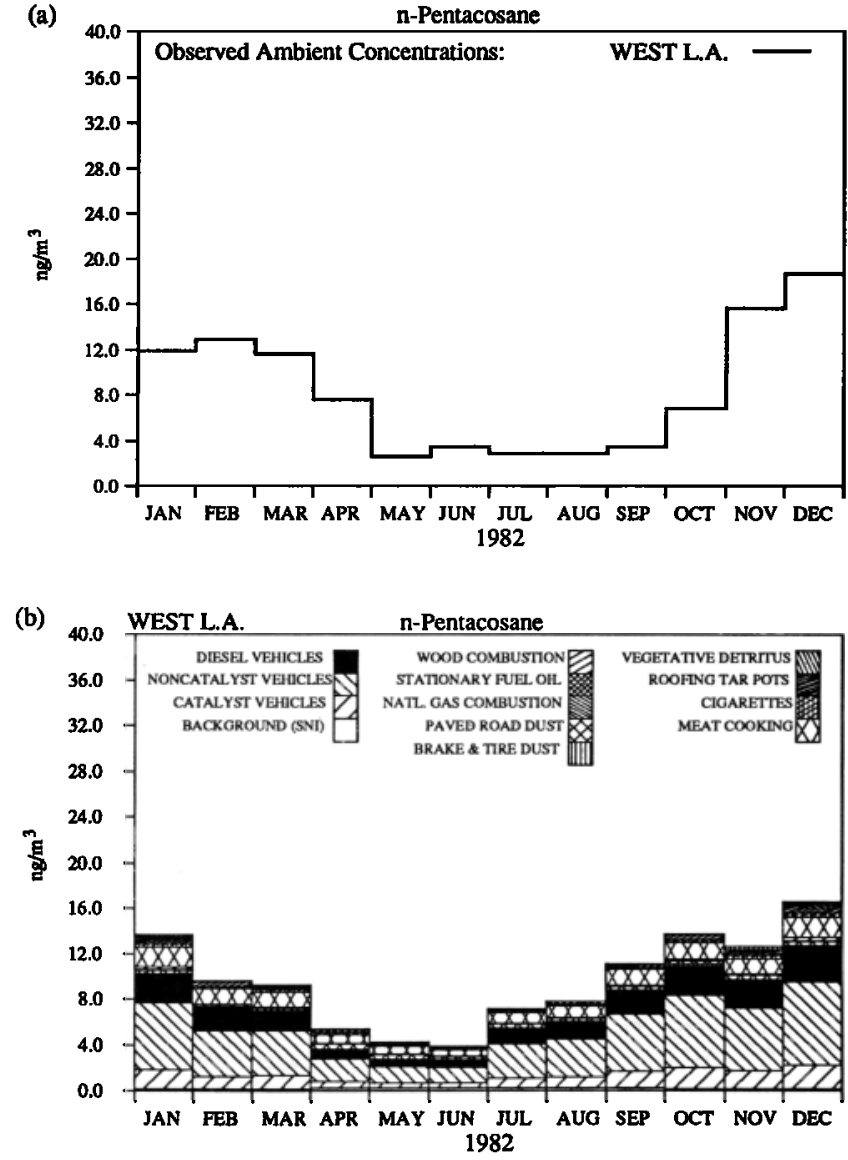

Figure 5. Monthly mean $n$-pentacosane $\left(\mathrm{C}_{25}\right)$ concentrations at west Los Angeles (1982): (a) observed and (b) predicted source contributions.

porting previous source attribution calculations for ambient outdoor cigarette smoke [Rogge et al., 1994].

\section{Polycyclic Aromatic Hydrocarbons}

Synthesized during incomplete combustion of fossil and contemporary renewable fuels (e.g., wood), particle-bound PAH are released to the atmosphere with fine particulate matter of micron and submicron dimensions [e.g., Katz and Chan, 1980; Miguel and Friedlander, 1978; Leuenberger et al., 1988; Albagli et al., 1974; Van Vaeck et al., 1979]. PAH have received appreciable attention because of their mutagenic and carcinogenic potential and their ubiquitous distribution within the biosphere [e.g., Bingham et al., 1980; International Agency for Research on Cancer, 1989; La Voie et al., 1979, 1985]. To determine the stability of such compounds in the urban atmosphere, PAH have been exposed to $\mathrm{OH}, \mathrm{O}_{3}, \mathrm{NO}, \mathrm{NO}_{2}, \mathrm{~N}_{2} \mathrm{O}_{5}$, and other oxidants and likewise to UV solar radiation [Brorström et al., 1983; Kamens et al., 1990; Nielson, 1988; Pitts et al., 1969, 1978, 1980, 1985; Khan et al., 1967; Kummler et al., 1969; Lane and Katz, 1977; Van Cauwenberghe, 1983; Grosjean, 1983; Fox and Olive, 1979; Inscoe, 1964]. These studies were conducted either with the test PAH deposited on glass, alumina, silica gel, or filter materials made of glass, quartz, or Tefion. Several other researchers have examined the decomposition of PAH contained in coal fly ash, diesel smoke, or wood smoke particles using outdoor smog chambers, fluidized bed photoreactors, 
(a)
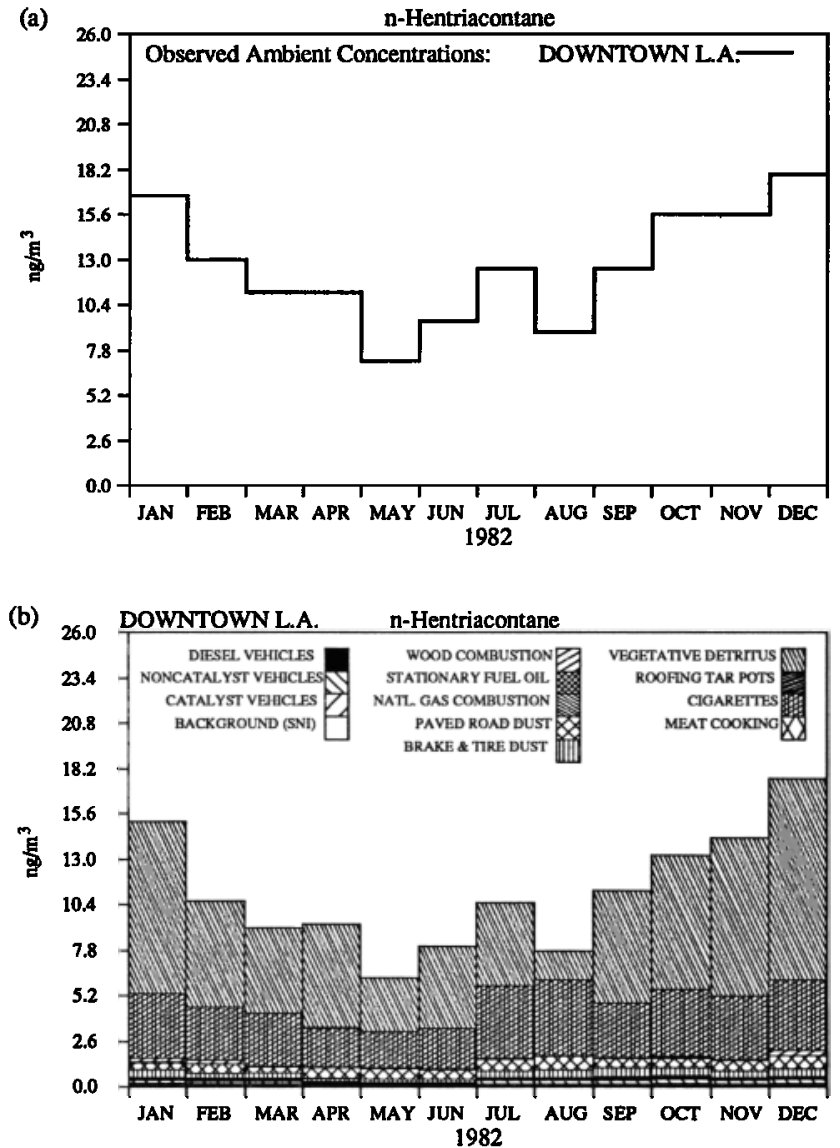

Figure 6. Monthly mean $n$-hentriacontane $\left(C_{31}\right)$ concentrations at downtown Los Angeles (1982): (a) observed and (b) predicted source contributions.

and other devices that keep the particulate matter suspended in air while exposing it to oxidants and UV radiation [e.g., Daisey et al., 1982; Kamens et al., 1984, 1986, 1990; Korfmacher et al., 1980, 1981].

None of these studies distinguished PAH degradation in the gas phase separately from heterogeneous reactions involving gas phase attack on particle phase organics. PAH cover a wide range of vapor pressures from $\sim 10^{-4}$ atm (naphthalene) to $\sim 10^{-15}$ atm (coronene) at $20^{\circ} \mathrm{C}$. These vapor pressures increase by approximately an order of magnitude when the ambient temperature increases by $20^{\circ} \mathrm{C}$ [Murray et al., 1974]. In the urban atmosphere, organic compounds with a vapor pressure of roughly $10^{-11} \mathrm{~atm}$ or less $\left(\right.$ at $20^{\circ} \mathrm{C}$ ) are exclusively found in the particle phase [Bidleman, 1988].

If PAH degradation occurs in the gas phase at an appreciable rate, then the ambient concentrations of low molecular weight PAH could be drastically reduced in the reactive urban atmosphere over the course of 1 day. In contrast, high molecular weight PAH, such as benzo[ghi]perylene and coronene, that are completely in the particle phase should be less affected by such degradation processes.

Figure 8 depicts both measurements and model predictions for ambient coronene concentrations for each month during 1982 at west Los Angeles. The mathematical model predicts ambient coronene concentrations that typically approximate the measured ambient concentrations quite well, except during the late summer months. The model calculations performed for inert elemental carbon and total carbon by Gray [1986] show a similar trend during late summer, suggesting that the overpredictions of primary species contributions during the summer at west Los Angeles is at least partially induced by transport calculations within the model itself. Unfortunately, the chromatographic separation of the samples acquired at the other sampling sites was stopped before coronene could elute from the column used; hence coronene predictions for these sites cannot be compared to measured ambient concentrations.

Benzo[ghi]perylene, another predominantly particle phase PAH, produces a similarly good match between model predictions and measured values at west Los Angeles. At downtown Los Angeles and Pasadena the model predictions of monthly averaged benzo[ghi]perylene concentrations show a rather flat concentration profile throughout the year, which does not match the much higher measured winter concentrations. The concentrations of both coronene and benzo[ghi]perylene in 1982 were dominated by emissions from noncatalyst gasolinepowered vehicles.

Figures 9a and 9b show model predictions of the annual average concentrations for 14 individual PAH compared to measured values at west Los Angeles. The annually averaged concentration of typical particle phase PAH, such as benzo[ghi]perylene and coronene, are slightly overpredicted by the model when compared to the measured annual mean concentrations. Lower molecular weight PAH ( $\leq$ MW 252) that par-

(a)
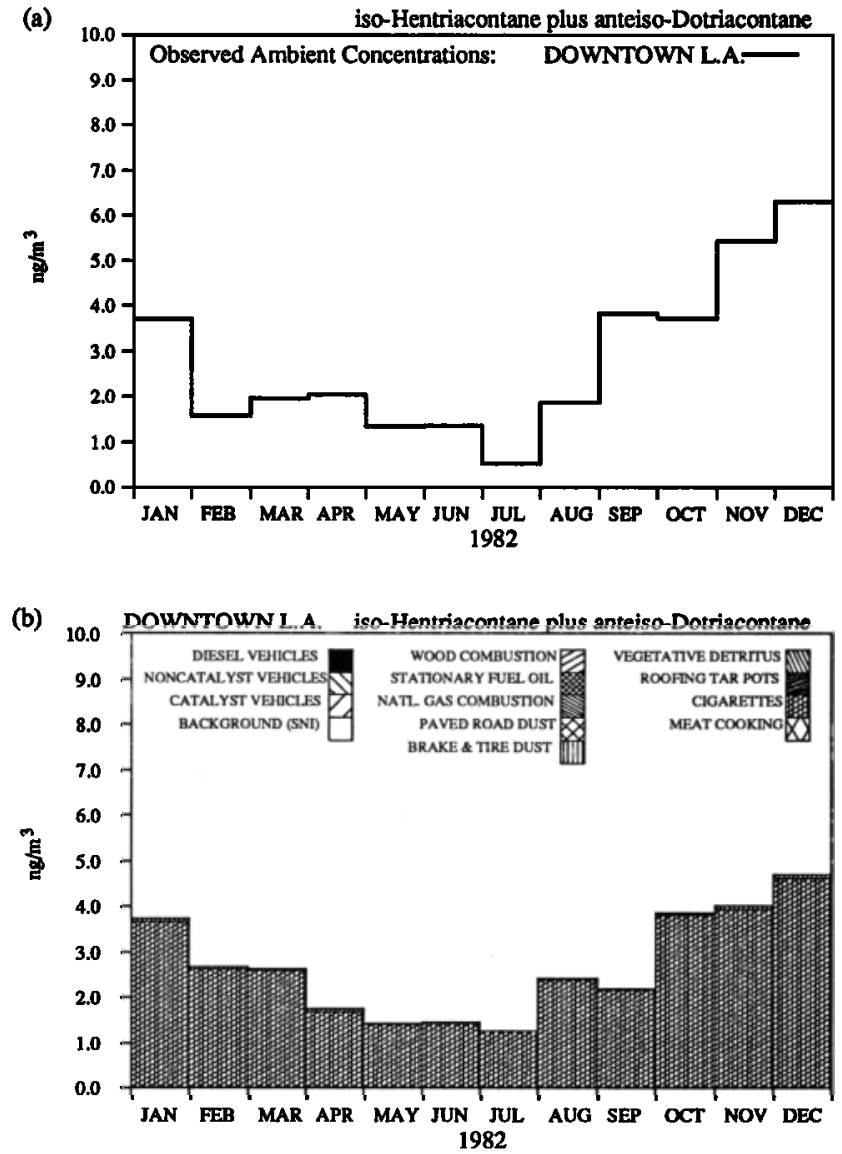

Figure 7. The sum of monthly mean isohentriacontane (iso$\mathrm{C}_{31}$ ) plus anteisodotriacontane (anteiso- $\mathrm{C}_{32}$ ) concentrations at downtown Los Angeles (1982): (a) observed and (b) predicted source contributions. 
tition between the particle and gas phases show drastically depleted measured ambient concentration levels when compared to the concentrations that would be present if all particle phase primary source emissions were conserved in the atmosphere. The discrepancy grows systematically with increasing vapor pressure. This result suggests that the highest molecular weight PAH that occur mainly in the particle phase are conserved in the atmosphere, while the lower molecular weight $\mathrm{PAH}$ are depleted by volatilization and/or chemical reaction in the atmosphere. At downtown Los Angeles and Pasadena, very similar results are found.

\section{Hopanes and Steranes}

It has been reported that petroleum compounds such as steranes and hopanes serve as tracer compounds which can be used to estimate vehicular source contributions to urban particulate matter concentrations [Mazurek and Simoneit, 1984; Simoneit, 1984; Rogge et al., 1993b]. Like coronene and benzo[ghi]perylene, these fossil petroleum markers are found exclusively in the particle phase and consequently are useful indicators for testing model performance. Figure 10 compares the measured and predicted total hopane and sterane concentrations at west Los Angeles. Several types of emission sources contribute to ambient concentrations, with vehicles as the main emitters [Simoneit, 1985; Rogge et al., 1993b, c; submitted manuscript, 1995a]. The agreement between measured con-

(a) 120 Coronene
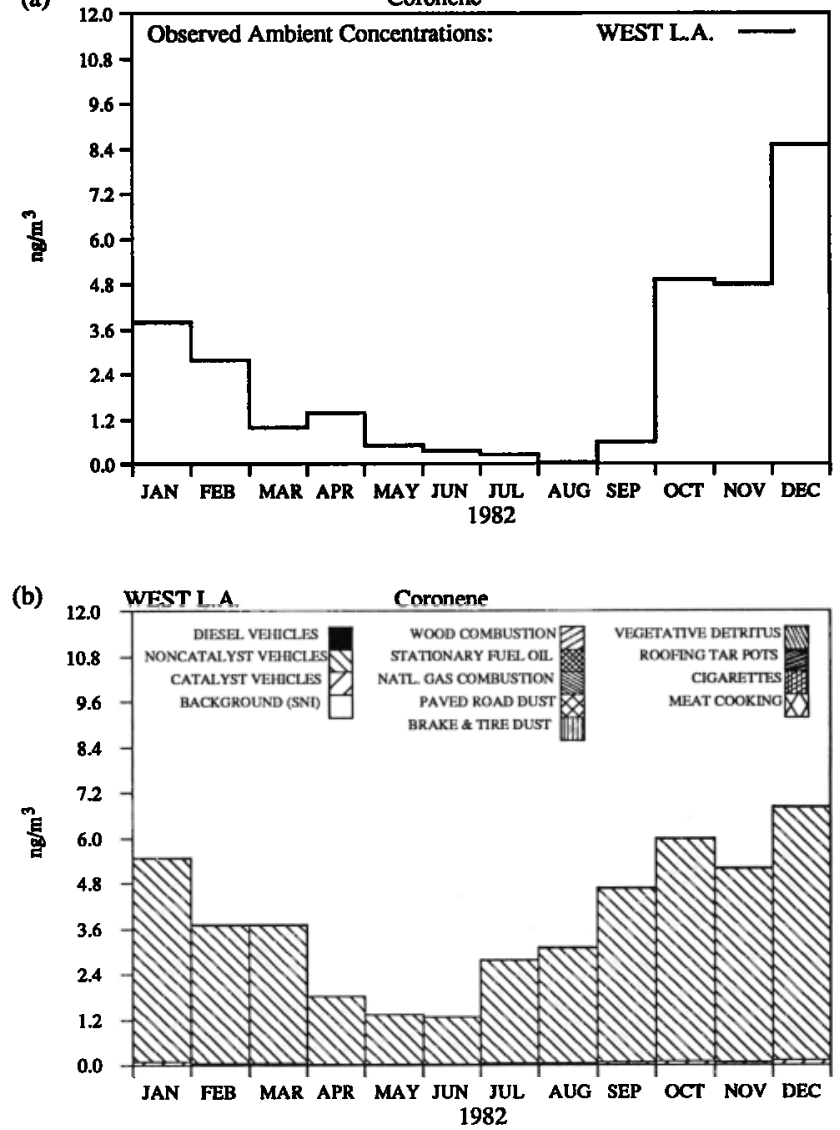

Figure 8. Monthly mean coronene concentrations at west Los Angeles (1982): (a) observed and (b) predicted source contributions.
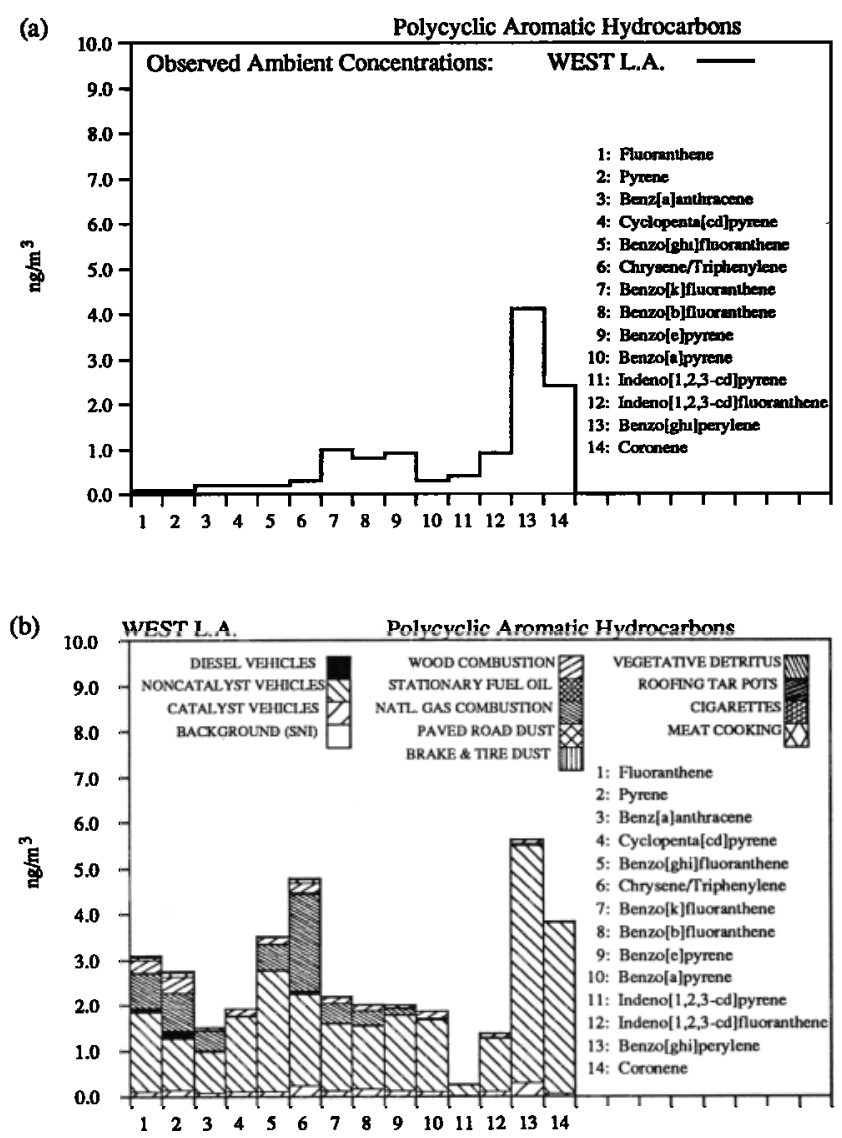

Figure 9. Annual mean polycyclic aromatic hydrocarbon (PAH) concentrations at west Los Angeles (1982): (a) observed and (b) predicted source contributions if no further volatilization or atmospheric chemical reactions were to take place.

centrations and model predictions is as good as was found for coronene and benzo[ghi]perylene. Again, the late summer concentrations predicted by the atmospheric transport model are somewhat higher than the observed values. At downtown Los Angeles and Pasadena the elevated winter concentrations measured are not matched by the model, a situation that also has been noted for the $n$-alkanes.

\section{Alkanoic and Alkenoic Acids}

The $n$-alkanoic acids ranging from $\mathrm{C}_{9}$ to $\mathrm{C}_{30}$ constitute the compound class with the highest measured ambient concentrations. Typically, $n$-alkanoic acids show a concentration profile in which the even carbon numbered homologues are predominant. The single most abundant $n$-alkanoic acid is $n$-hexadecanoic acid $\left(\mathrm{C}_{16}\right)$, followed by $n$-octadecanoic acid $\left(\mathrm{C}_{18}\right)$.

The measured and predicted annual mean $n$-alkanoic acid concentrations at west Los Angeles are shown in Figure 11. The predicted and observed concentration patterns for $n$ alkanoic acids $>\mathrm{C}_{13}$ are very similar, although the predicted ambient concentrations fall short of the measured values by about $50 \%$. It is possible that cooking with seed oils that are rich in saturated and unsaturated fatty acids may account for an appreciable portion of the observed differences between predictions and observations for the $\mathrm{C}_{16}$ and $\mathrm{C}_{18}$ fatty acids. 

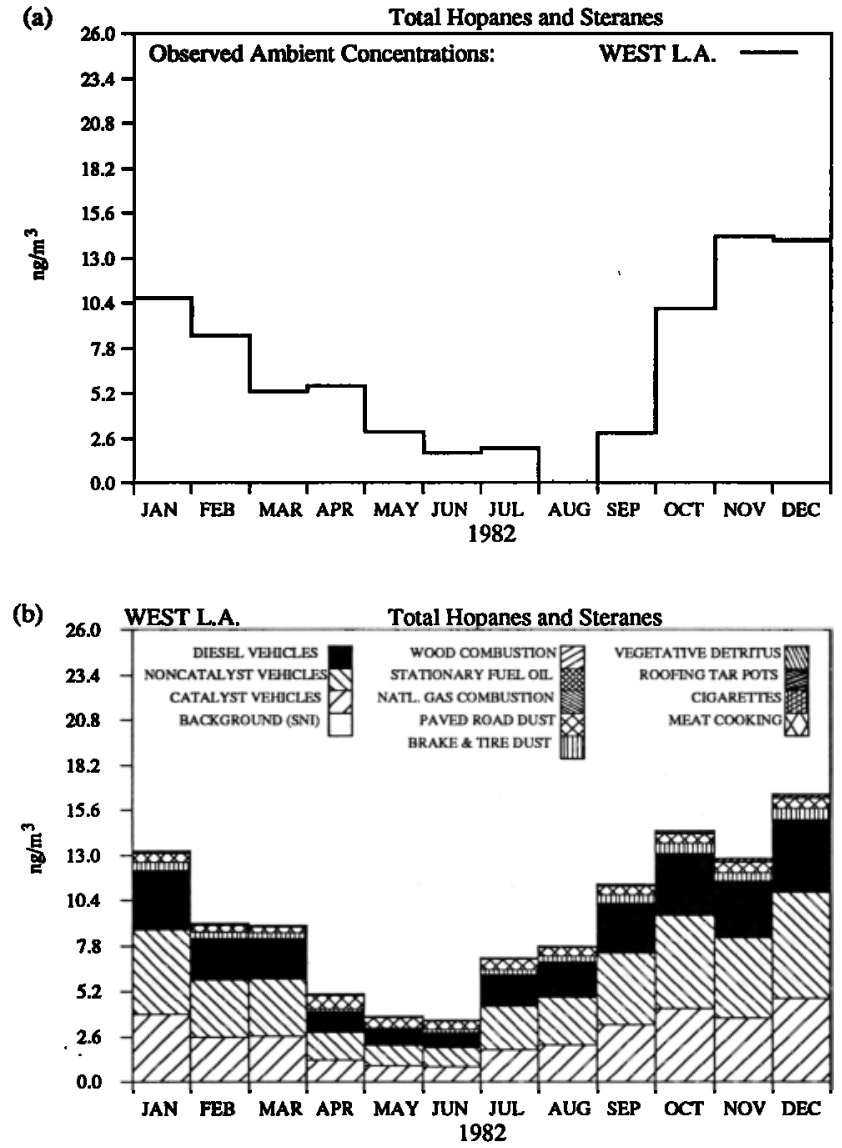

Figure 10. Monthly mean total hopane and sterane concentrations at west Los Angeles (1982): (a) observed and (b) predicted source contributions.

While $n$-alkanoic acids $<\mathrm{C}_{13}$ are mainly contributed from vehicular emissions, $n$-hexadecanoic acid shows a multitude of source contributions, most importantly meat-cooking emissions. Higher $n$-alkanoic acids $>\mathrm{C}_{18}$ are typically contributed from wood combustion. The observed and predicted $n$ alkanoic acid concentration distributions at downtown Los Angeles and Pasadena are very similar to that for west Los Angeles and therefore are not shown here.

The compound $n$-octadecenoic acid (oleic acid) is a monounsaturated fatty acid typically released from food cooking and wood combustion. Predicted concentration levels are higher than measured values during the summer season, indicating that oleic acid concentrations in the reactive urban atmosphere are depleted by atmospheric chemical reactions as proposed by several researchers [Kawamura and Gagosian, 1987; Kawamura and Kaplan, 1987; Killops, 1986]. The $n$ octadecenoic acid is typically released together with its saturated homologue, stearic acid, that is also underpredicted by the model, probably because of the lack of emissions data for cooking with vegetable oils. Consequently, the daily emission rate of oleic acid is probably higher than in the present emission inventory, suggesting an even greater rate of atmospheric degradation than would be inferred by comparison of the present modeling results to atmospheric measurements.

\section{Aliphatic Dicarboxylic and Aromatic Polycarboxylic Acids}

Aliphatic dicarboxylic acids are known to be formed under photochemical smog conditions from gas phase precursor compounds. These atmospheric reaction products have very low vapor pressures and thus condense onto preexisting particulate matter [Appel et al., 1980; Cronn et al., 1977; Grosjean, 1977; Grosjean and Friedlander, 1980; Rogge et al., 1993a; Satsumabayashi et al., 1989].

Aromatic polycarboxylic acids also have been reported in airborne particulate matter [Cautreels and Van Cauwenberghe, 1976; Matsumoto and Hanya, 1980; Rogge et al., 1993a; Satsumbayashi et al., 1989; Simoneit, 1985; Yokouchi and Ambe, 1986]. They may result from atmospheric PAH degradation [Rogge et $a l .$, 1993a]. Phthalic acid, in particular, may result from degradation of phthalate esters (plasticizers) [Rogge et al., 1993a].

The direct primary emission of aliphatic dicarboxylic acids and aromatic polycarboxylic acids from sources has not been extensively investigated in the past. During the source emissions characterization program conducted as part of the present study [Rogge et al., 1991, 1993b, c, d, e, 1994; submitted manuscripts, 1995a, b, c] the aliphatic dicarboxylic and aromatic polycarboxylic acids present in primary source emissions were measured and were found only in trace amounts. The only sources studied here that release detectable amounts of
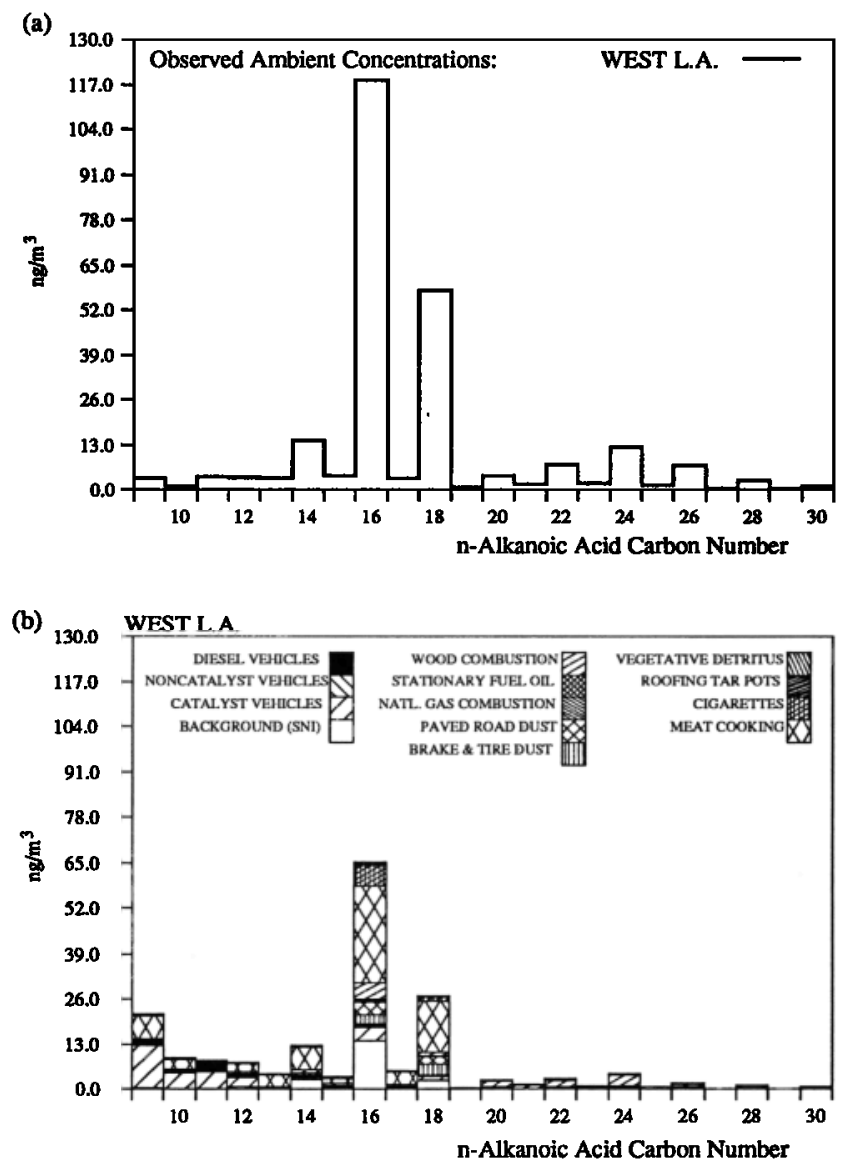

Figure 11. Annual mean $n$-alkanoic acid concentrations at west Los Angeles (1982): (a) observed and (b) predicted source contributions if no further volatilization or atmospheric chemical reactions were to take place. 
aliphatic dicarboxylic acids are fireplace combustion of wood and meat-cooking operations. Figure $2 \mathrm{~b}$ suggests that primary source emissions of individual aliphatic dicarboxylic acids, ranging from propanedioic acid to nonanedioic acid, are far below the quantities needed to account for the measured levels. At west Los Angeles the model predictions for the concentrations of butanedioic acid, pentanedioic acid, methylpentanedioic acid, octanedioic acid, and nonanedioic acid due to primary source emissions are negligible while the model predictions for primary propanedioic acid, hydroxybutanedioic acid, and hexanedioic acid range from 2 to $7 \mathrm{ng} \mathrm{m}^{-3}$. This indicates that indeed most of the aliphatic dicarboxylic acids found in airborne particles are the product of atmospheric chemical reactions that occur in photochemical smog. The same results have been found at downtown Los Angeles and Pasadena.

The primary source contributions to aromatic polycarboxylic acid concentrations are even smaller than that computed for the aliphatic dicarboxylic acids. The measured ambient concentrations reveal a seasonal concentration pattern similar to that found for the aliphatic dicarboxylic acids, again suggesting that the aromatic polycarboxylic acids are produced mainly by atmospheric chemical reactions. For the measured ambient concentrations of aromatic polycarboxylic acids the interested reader is referred to Rogge et al. [1993a].

\section{Resin Acids Wood Smoke Markers}

The combustion of coniferous wood is the most important source of resinous organic acid emissions to the atmosphere [Simoneit et al., 1993; Simoneit and Mazurek, 1982; Standley and Simoneit, 1987, 1990, 1994; Rogge et al., submitted manuscript, 1995c]. The combustion of wood for space heating and for home recreational purposes in the Los Angeles area occurs mostly during the winter months and consists mainly of the combustion of wood logs in open fireplaces.

Air quality predictions for wood smoke markers are compared to measured ambient concentrations in Figure 12. At all three urban sites considered the predicted concentrations follow the seasonal use of wood as a domestic fuel. At west Los Angeles the predicted concentrations closely follow the measured concentration levels. At Pasadena the model predictions are far lower than the measured values, suggesting greater use of wood fuels in Pasadena than is typical of Los Angeles as a whole (which is likely considering the unusually large number of trees and fireplaces in Pasadena). At all three monitoring sites, wood combustion seems to be underpredicted during the month of November.

\section{Conclusions}

A mathematical model that simulates pollutant advection and dispersion has been used to predict source contributions to monthly averaged fine particle-bound organic compound concentrations at three sites within an $80 \mathrm{~km} \times 80 \mathrm{~km}$ modeling domain centered over Los Angeles. Typically, good agreement between measured concentration levels and air quality model predictions has been found for stable organic compounds that are exclusively present in the particle phase, such as $n$-alkanes, isoalkanes, and anteisoalkanes, higher molecular weight PAH (e.g., coronene, benzo[ghi]perylene), and fossil petroleum compounds such as hopanes and steranes.

Vegetative detritus released as fine particles shed from waxy
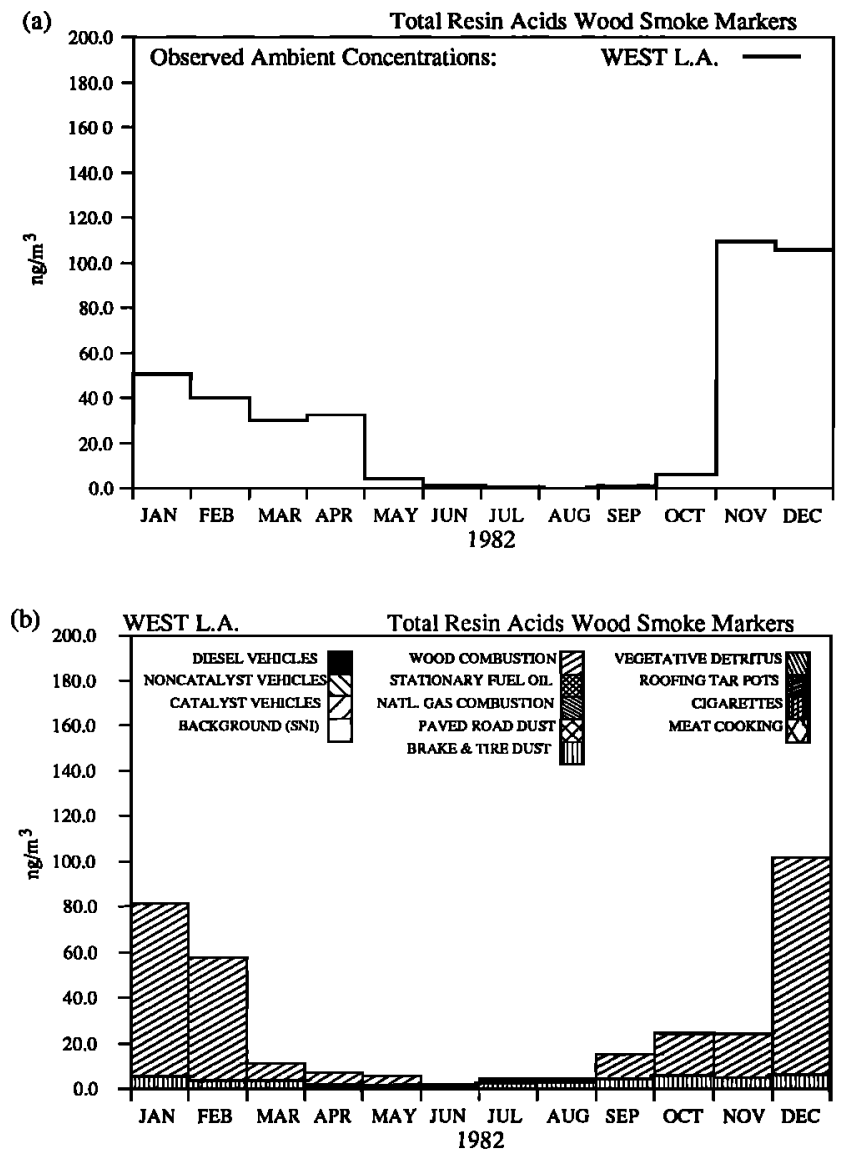

Figure 12. Monthly mean total resin acids wood smoke marker concentrations at west Los Angeles (1982): (a) observed and (b) predicted source contributions.

leaf surfaces contribute together with cigarette smoke to the higher molecular weight $n$-alkane concentration levels measured throughout the study area. Isoalkanes and anteisoalkanes, characteristic markers for cigarette smoke, show predicted concentrations that agree well with measured concentration levels. High molecular weight $\mathrm{PAH}$, such as benzo[ghi]perylene and coronene, show predicted and measured monthly concentration levels that are in particularly good agreement at West Los Angeles. Low molecular weight PAH concentrations are drastically overpredicted by the model, because volatilization and/or atmospheric chemical reactions are not represented in the present transport calculations.

The $n$-alkanoic acid concentrations are typically underpredicted by the model, suggesting that other sources not yet considered, such as cooking with vegetable oils, could contribute significant amounts of $n$-alkanoic acids. Aliphatic dicarboxylic acids and aromatic polycarboxylic acids are released only in small amounts to the urban atmosphere from primary aerosol sources, indicating that such compounds are indeed mainly the result of atmospheric formation processes that occur in photochemical smog.

Resin acids wood smoke marker concentration predictions reveal a seasonal pattern that follows the use of wood as a domestic fuel. The model predictions suggest that the use of wood in residential fireplaces is underestimated during November 1982 at all three sampling sites and at Pasadena during the entire heating season. 
The source emission data and air quality modeling procedures developed here are capable of accounting for both the atmospheric concentration of and source contributions to many individual particle phase organic compounds. The source types considered are found widely throughout the world. Thus these modeling methods and certain of the source compositional data may be useful in diagnosing the origin of organic compound concentrations encountered in other urban settings. Long-distance transport calculations analogous to the air quality modeling calculations in the present study could be performed for those compounds that are particularly stable chemically.

Acknowledgments. The air quality modeling study reported here was supported by the Electric Power Research Institute under agreement RP3189-3. The emissions data for single organic compounds were acquired with the support of the U.S. Environmental Protection Agency under agreement R-819714-01-0 and the California Air Resources Board under agreement A932-127. Analysis of the atmospheric aerosol was supported by the South Coast Air Quality Management District.

\section{References}

Albagli, A., L. Eagan, H. Oja, and L. Dubois, Size-distribution measurements of airborne particles, Atmos. Environ., 8, 201-202, 1974.

Appel, B. R., S. M. Wall, and R. L. Knights, Characterization of carbonaceous materials in atmospheric aerosols by high-resolution mass spectrometric thermal analysis, in The Character and Origin of Smog Aerosols, Adv. Environ. Sci. Technol., vol. 9, edited by J. N. Pitts Jr. and R. L. Metcalf, pp. 353-365, John Wiley, New York, 1980

Bidleman, T. F., Atmospheric processes, Environ. Sct Technol., 22, 361-367, 1988

Bingham, E., R. P. Trosset, and D. Warshawsky, Carcinogenic potential of petroleum hydrocarbons, J. Environ. Pathol. Toxicol., 3, 483$563,1980$.

Brorstrom, E., P. Grennfelt, and A. Lindskog, The effect of nitrogen dioxide and ozone on the decomposition of particle-associated polycyclic aromatic hydrocarbons during sampling from the atmosphere, Atmos. Environ., 17, 601-605, 1983.

Cass, G. R., Methods for sulfate air quality management with applications to Los Angeles, Ph.D. thesis, Calif. Inst. of Technol., Pasadena, 1977.

Cass, G. R., Sulfate air quality control strategy design, Atmos. Environ., $15,1227-1249,1981$.

Cautreels, W., and K. Van Cauwenberghe, Determination of organic compounds in airborne particulate matter by gas chromatographymass spectrometry, Atmos. Environ., 10, 447-457, 1976.

Cronn, D. R., R. J. Charlson, and B. R. Appel, A survey of the molecular nature of primary and secondary components of particles in urban air by high-resolution mass spectrometry, Atmos. Environ., 11, 929-937, 1977.

Daisey, J. M., C. G. Lewandowski, and M. Zorz, A photoreactor for investigations of the degradation of particle-bound polycyclic aromatic hydrocarbons under simulated atmospheric conditions, Environ. Sci. Technol., 16, 857-861, 1982.

Drivas, P. J., and F. H. Shair, The chemistry, dispersion, and transport of air pollutants emitted from fossil fuel power plants in CaliforniaTransport of plumes associated with complex coastal meterology, Rep. ARB-915, Div. of Chem. and Chem. Eng., Calif. Inst. of Technol., Pasadena, 1975.

Fox, M. A., and S. Olive, Photooxidation of anthracene on atmospheric particulate matter, Science, 205, 582-583, 1979.

Gray, H. A., Control of atmospheric fine primary carbon particle concentrations, Ph.D. thesis, Calif. Inst. of Technol., Pasadena, 1986.

Gray, H. A., G. R. Cass, J. J. Huntzicker, E. K. Heyerdahl, and J. A. Rau, Characteristics of atmospheric organic and elemental carbon particle concentrations in Los Angeles, Environ. Sci. Technol., 20 , $580-589,1986$.
Grosjean, D., Aerosols, in Ozone and Other Photochemical Oxidants, chap. 3, pp. 45-125, Natl. Acad. of Sci., Washington, D. C., 1977.

Grosjean, D., Polycyclic aromatic hydrocarbons in Los Angeles air collected on teflon, glass and quartz filters, Atmos. Environ., 12, 2565-2573, 1983.

Grosjean, D., and S. K. Friedlander, Formation of organic aerosols from cyclic olefins and diolefins, in The Character and Origin of Smog Aerosols, Adv. Environ. Sci. Technol., vol. 9, edited by J. N. Pitts Jr. and R. L. Metcalf, pp. 435-473, John Wiley, New York, 1980.

Grosjean, D., and J. H. Seinfeld, Parameterization of the formation potential of secondary organic aerosols, Atmos. Environ., 23, 17331747, 1989.

Hatakeyama, S., T. Tanonaka, J. Weng, H. Bandow, H. Takagi, and H. Akimoto, Ozone-cyclohexene reaction in air: Quantitative analysis of particulate products and the reaction mechanism, Environ. Sci. Technol., 19, 935-942, 1985.

Hatakeyama, S., M. Ohno, J. Weng, H. Takagi, and H. Akimoto, Mechanism for the formation of gaseous and particulate products from ozone-cycloalkene reactions in air, Environ. Sci. Technol., 21, 52-57, 1987.

Hildemann, L. M., G. R. Markowski, and G. R. Cass, Chemical composition of emissions from urban sources of fine organic aerosol, Environ. Scl. Technol., 25, 744-759, 1991a.

Hildemann, L. M., M. A. Mazurek, G. R. Cass, and B. R. T. Simoneit, Quantitative characterization of urban sources of organic aerosol by high-resolution gas chromatography, Environ. Sci. Technol., 25, 1311-1325, 1991b.

Hildemann, L. M., G. R. Cass, M. A. Mazurek, and B. R. T. Simoneit, Mathematical modeling of urban organic aerosol: Properties measured by high-resolution gas chromatography, Environ. Sci. Technol., 27, 2045-2055, 1993.

Hildemann, L. M., D. B. Klinedinst, G. A. Klouda, L. A. Currie, and G. R. Cass, Sources of urban contemporary carbon aerosol, Environ. Scl. Technol., 28, 1565-1576, 1994a.

Hildemann, L. M., M. A. Mazurek, G. R. Cass, and B. R. T. Simoneit, Seasonal trends in Los Angeles ambient organic aerosol observed by high-resolution gas chromatography, Aerosol Sci. Technol., 20, 303317, 1994b.

Hildemann, L. M., W. F. Rogge, G. R. Cass, M. A. Mazurek, and B. R. T. Simoneit, Contribution of primary aerosol emissions from vegetation-derived sources to fine particle concentrations in Los Angeles, $J$. Geophys. Res., this issue.

International Agency for Research on Cancer Working Group, Evaluation of carcinogenic risks to humans-Diesel and gasoline engine exhausts and some nitroarenes, Cancer Res., 46, 41-155, 1989.

Inscoe, M., Photochemical changes in thin layer chromatograms of polycyclic aromatic hydrocarbons, Anal. Chem., 36, 2505-2506, 1964. Kamens, R. M., G. D. Rivers, J. M. Perry, D. A. Bell, R. F. Paylor Jr., R. G. Goodman, and L. D. Claxton, Mutagenic changes in dilute wood smoke as it ages and reacts with ozone and nitrogen dioxide: An outdoor chamber study, Environ. Sci. Technol., 18, 523-530, 1984.

Kamens, R. M., J. N. Fulcher, and Z. Guo, Effects of temperature on wood soot PAH decay in atmospheres with sunlight and low $\mathrm{NO}_{x}$, Atmos. Environ., 20, 1579-1587, 1986.

Kamens, R. M., J. Guo, Z. Guo, and S. R. McDow, Polynuclear aromatic hydrocarbon degradation by heterogeneous reactions with $\mathrm{N}_{2} \mathrm{O}_{5}$ on atmospheric particles, Atmos. Environ. Part A, 24, 11611173,1990

Katz, M., and C. Chan, Comparative distribution of eight polycyclic aromatıc hydrocarbons in airborne particulates collected by conventional high-volume sampling and by size fractionation, Environ. Sci. Technol., 14, 838-843, 1980.

Kawamura, K., and R. B. Gagosian, Implication of $\omega$-oxocarboxylic acids in the remote marine atmosphere for photo-oxidation of unsaturated fatty acids, Nature, 325, 320-332, 1987.

Kawamura, K., and I. R. Kaplan, Motor exhaust emissions as a primary source for dicarboxylic acids in Los Angeles ambient air, Environ. Sci. Technol., 21, 105-110, 1987.

Khan, A. U., J. N. Pitts Jr., and E. B. Smith, Singlet oxygen in the environmental sciences: The role of singlet molecular oxygen in the production of photochemical air pollution, Environ. Sci. Technol., 1, 656-657, 1967.

Killops, S. D., Action of ozone on methyl octadec-9-enoate in polar solvents, Water Res., 20, 167-171, 1986

Kolattukudy, P. E., Plant waxes, Lipids, 5, 259-275, 1970. 
Korfmacher, W. A., E. L. Wehry, G. Mamantov, and D. F. S. Natusch, Resistance to photochemical decomposition of polycyclic aromatic hydrocarbons vapor-adsorbed on coal fly ash, Envtron. Sci. Technol., 14, 1094-1099, 1980.

Korfmacher, W. A., E. L. Wehry, D. F. S. Natusch, and T. Mauney, Nonphotochemical decomposition of fluorene vapor-adsorbed on coal fly ash, Environ. Scl. Technol., 15, 1370-1375, 1981.

Kummler, R. H., M. H. Bortner, and T. Baurer, The Hartley photolysis of ozone as a source of singlet oxygen in polluted atmospheres, Environ. Sci. Technol., 3, 248-250, 1969.

Lane, D. A., and M. Katz, The photomodification of benzo(a)pyrene, benzo(b)fluoranthene and benzo(k)fluoranthene under simulated atmospheric conditions, in Fate of Pollutants in the Air and Water Environment, part 2, Chemical and Biological Fate of Pollutants in the Environment, edited by I. H. Suffet, pp. 137-154, John Wiley, New York, 1977.

La Voie, E., V. Bedenko, N. Hirota, S. S. Hecht, and D. A. Hoffmann, A comparison of the mutagenicity, tumor-initiating activity and complete carcinogenicity of polynuclear aromatic hydrocarbons, in Polynuclear Aromatic Hydrocarbons: Chemistry and Biology, Carcınogenesis and Mutagenesis, edited by M. Cooke and A. J. Dennis, pp. 451-471, Battelle, Columbus, Ohio, 1979.

La Voie, E. J., A. Shigematsu, E. A. Adams, N. G. Geddie, and J. E. Rice, Quinolines and benzoquinolines: Studies related to their metabolism, mutagenicity, tumor-initiating activity, and carcinogenicity, in Polynuclear Aromatic Hydrocarbons: A Decade of Progress, edited by M. Cooke and A. J. Dennis, pp. 503-518, Battelle, Columbus, Ohio, 1985.

Leuenberger, C., J. Czucwa, H. Heyerdahl, and W. Giger, Aliphatic and polycyclic aromatic hydrocarbons in urban rain, snow and fog, Atmos. Environ., 22, 695-705, 1988.

Matsumoto, G., and T. Hanya, Organic constituents in atmospheric fallout in the Tokyo area, Atmos. Environ., 14, 1409-1419, 1980.

Mazurek, M. A., and B. R. T. Simoneit, Characterization of biogenic and petroleum derived organic matter in aerosols over remote, rural and urban areas, in Identification and Analysus of Organic Pollutants in Air, edited by L. H. Keith, pp. 353-370, Butterworth-Heinemann, Stoneham, Mass., 1984.

Mazurek, M. A., B. R. T. Simoneit, G. R. Cass, and H. A. Gray, Quantitative high-resolution gas chromatography and highresolution gas chromatography/mass spectrometry analysis of carbonaceous fine aerosol particles, Int. J. Environ. Anal. Chem., 29, 119$139,1987$.

Mazurek, M. A., G. R. Cass, and B. R. T. Simoneit, Interpretation of high-resolution gas chromatography and high-resolution gas chromatography/mass spectrometry data acquired from atmospheric organic aerosol samples, Aerosol Sci. Technol., 10, 408-419, 1989.

Mazurek, M. A., G. R. Cass, and B. R. T. Simoneit, Biological input to visibility-reducing aerosol particles in the remote arid Southwestern United States, Environ. Sci. Technol., 25, 684-694, 1991.

Miguel, A., and S. K. Friedlander, Distribution of benzo[a]pyrene and coronene with respect to particle size in Pasadena aerosols in the submicron range, Atmos. Environ., 12, 2407-2413, 1978.

Murray, J. J., R. F. Pottie, and C. Pupp, The vapor pressures and enthalpies of sublimation of five polycyclic aromatic hydrocarbons, Can. J. Chem., 52, 557-563, 1974.

Nielson, T., The decay of benzo[a]pyrene and cyclopenta[cd]pyrene in the atmosphere, Atmos. Environ., 22, 2249-2254, 1988.

Pitts, J. N., Jr., A. U. Khan, E. B. Smith, and R. P. Wayne, Singlet oxygen in the environmental sciences: Singlet molecular oxygen and photochemical air pollution, Environ. Sci. Technol., 3, 241-247, 1969.

Pitts, J. N., Jr., K. A. Van Cauwenberghe, D. Grosjean, J. P. Schmid, D. R. Fitz, W. L. Belser Jr., G. B. Knudson, and P. M. Hynds, Atmospheric reactions of polycyclic aromatic hydrocarbons: Facile formation of mutagenic nitro derivatives, Science, 202, 515-519, 1978.

Pitts, J. N., Jr., D. M. Lockensgard, P. S. Ripley, K. A. Van Cauwenberghe, L. Van Vaeck, S. D. Schaffer, A. J. Thill, and W. L. Belser Jr., Atmospheric epoxidation of benzo[a]pyrene by ozone: Formation of the metabolite benzo[a]pyrene-4,5-oxide, Science, 210, 1347$1349,1980$.

Pitts, J. N., Jr., B. Zielinska, J. A. Sweetman, R. Atkinson, and A. M. Winer, Reactions of adsorbed pyrene and perylene with gaseous $\mathrm{N}_{2} \mathrm{O}_{5}$ under simulated atmospheric conditions, Atmos. Environ., 19, 911-915, 1985
Rogge, W. F., L. M. Hildemann, M. A. Mazurek, G. R. Cass, and B. R. T. Simoneit, Sources of fine organic aerosol, 1, Charbroilers and meat cooking operations, Environ. Sct. Technol., 25, 1112-1125, 1991.

Rogge, W. F., M. A. Mazurek, L. M. Hildemann, G. R. Cass, and B. R. T. Simoneit, Quantification of urban organic aerosols at a molecular level: Identification, abundance, and seasonal variation, Atmos. Environ. Part A, 27, 1309-1330, 1993a.

Rogge, W. F., L. M. Hildemann, M. A. Mazurek, G. R. Cass, and B. R. T. Simoneit, Sources of fine organic aerosol, 2, Noncatalyst and catalyst-equipped automobiles and heavy-duty diesel trucks, Environ. Scl. Technol., 27, 636-651, 1993b.

Rogge, W. F., L. M. Hildemann, M. A. Mazurek, G. R. Cass, and B. R. T. Simoneit, Sources of fine organic aerosol, 3, Road dust, tire debris, and organometallic brake lining dust-Roads as sources and sinks, Environ. Sct. Technol., 27, 1892-1904, 1993c.

Rogge, W. F., L. M. Hildemann, M. A. Mazurek, G. R. Cass, and B. R. T. Simoneit, Sources of fine organic aerosol, 4, Particulate abrasion products from leaf surfaces of urban plants, Environ. Sci. Technol., 27, 2700-2711, 1993d.

Rogge, W. F., L. M. Hildemann, M. A. Mazurek, G. R. Cass, and B. R. T. Simoneit, Sources of fine organic aerosol, 5, Natural gas home appliances, Environ. Sci. Technol., 27, 2736-2744, 1993e.

Rogge, W. F., L. M. Hildemann, M. A. Mazurek, G. R. Cass, and B. R. T. Simoneit, Sources of fine organic aerosol, 6, Cigarette smoke in the urban atmosphere, Environ. Scl. Technol., 28, 1375-1388, 1994. Satsumabayashi, H., H. Kurita, Y. Yokouchi, and H. Ueda, Mono- and di-carboxylic acids under long-range transport of air pollution in central Japan, Tellus, Ser. B, 41, 219-229, 1989.

Simoneit, B. R. T., Organic matter in eolian dusts over the Atlantic ocean, Mar. Chem., 5, 443-464, 1977.

Simoneit, B. R. T., Biogenic lipids in eolian particulates collected over the ocean, in Proceedings Carbonaceous Particles in the Atmosphere, Rep. LBL-9037, edited by T. Novakov, pp. 233-244, Natl. Sci. Found., Washington, D. C., 1979.

Simoneit, B. R. T., and M. A. Mazurek, Organic matter of the troposphere, II, Natural background of biogenic lipid matter in aerosols over the rural western United States, Atmos. Environ., 16, 2139$2159,1982$.

Simoneit, B. R. T., Organic matter of the troposphere, III, Characterization and sources of petroleum and pyrogenic residues in aerosols over the Western United States, Atmos. Environ., 18, 51-67, 1984.

Simoneit, B. R. T., Application of molecular marker analysis to vehicular exhaust for source reconciliations, Int $J$ Environ. Anal. Chem., 22, 203-233, 1985.

Simoneit, B. R. T., R. E. Cox, and L. J. Standley, Organic matter of the troposphere, IV, Lipids in Harmattan aerosols of Nigeria, Atmos. Environ., 22, 983-1004, 1988.

Simoneit, B. R. T., P. T. Crisp, M. A. Mazurek, and L. J. Standley, Composition of extractable organic matter of aerosols from the Blue Mountains and southeast coast of Australia, Environ. Int., 17, 405419, 1991.

Simoneit, B. R. T., W. F. Rogge, M. A. Mazurek, L. J. Standley, L. M. Hildemann, and G. R. Cass, Lignin pyrolysis products, lignans and resin acids as specific tracers of plant classes in emissions from biomass combustion, Environ. Sci. Technol., 27, 2533-2541, 1993.

Standley, L. J., and B. R. T. Simoneit, Characterization of extractable plant wax, resin, and thermally matured components in smoke particles from prescribed burns, Environ. Sci. Technol., 21, 163-169, 1987.

Standley, L. J., and B. R. T. Simoneit, Preliminary correlation of organic molecular tracers in residential wood smoke with the source of fuel, Atmos. Environ. Part B, 24, 67-73, 1990.

Standley, L. J., and B. R. T. Simoneit, Resin diterpenoids as tracers for biomass combustion aerosols, J. Atmos. Chem., 18, 1-15, 1994.

Tao, Y., and P. H. McMurry, Vapor pressures and surface free energies of C14-C18 monocarboxylic acids and $\mathrm{C} 5$ and $\mathrm{C} 6$ dicarboxylic acids, Environ. Sci. Technol., 23, 1519-1523, 1989.

Van Cauwenberghe, K., Atmospheric reactions of PAH, in Handbook of Polycyclic Aromatic Hydrocarbons, vol. 2, Emission Sources and Recent Progress in Analytical Chemistry, edited by A. Bjørseth and T. Ramdahl, pp. 351-384, Marcel Dekker, New York, 1983.

Van Vaeck, L., G. Broddin, and K. Van Cauwenberghe, Differences in particle size distributions of major organic pollutants in ambient aerosols in urban, rural and seashore areas, Environ. Sci. Technol., 13, 1494-1502, 1979. 
Yokouchi, Y., and Y. Ambe, Characterization of polar organics in airborne particulate matter, Atmos. Environ., 20, 1727-1734, 1986.

G. R. Cass (corresponding author), Environmental Engineering Science Department and Environmental Quality Laboratory, W. M. Keck

Laboratories 138-78, California Institute of Technology, Pasadena, CA 91125.

L. M. Hildemann, Department of Civil Engineering, Stanford University, Stanford, CA 94305.

M. A. Mazurek, Environmental Chemistry Division, Brookhaven National Laboratory, Upton, NY 11973.
W. F. Rogge, Department of Civil and Environmental Engineering, Florida International University, University Park, Miami, FL 33199.

B. R. T. Simoneit, Petroleum and Environmental Geochemistry Group, College of Oceanic and Atmospheric Sciences, Oregon State University, Corvallis, OR 97331.

(Received October 25, 1994; revised June 1, 1995; accepted June 8, 1995.) 